\title{
Review Article \\ Renoprotective Effects of the Dipeptidyl Peptidase-4 Inhibitor Sitagliptin: A Review in Type 2 Diabetes
}

\author{
Cristina Mega, ${ }^{1,2,3}$ Edite Teixeira-de-Lemos, ${ }^{1,2}$ Rosa Fernandes, ${ }^{3,4}$ and Flávio Reis ${ }^{3,4}$ \\ ${ }^{1}$ Agrarian School of Viseu (ESAV), Polytechnic Institute of Viseu (IPV), 3500-606 Viseu, Portugal \\ ${ }^{2}$ Centre for the Study of Education, Technologies and Health (CI\&DETS), Polytechnic Institute of Viseu (IPV), 3500-606 Viseu, Portugal \\ ${ }^{3}$ Institute of Pharmacology and Experimental Therapeutics and Institute for Biomedical Imaging and Life Sciences (IBILI), Faculty of \\ Medicine, University of Coimbra, 3000-548 Coimbra, Portugal \\ ${ }^{4}$ CNC.IBILI Research Consortium, University of Coimbra, 3004-504 Coimbra, Portugal
}

Correspondence should be addressed to Rosa Fernandes; rcfernandes@fmed.uc.pt and Flávio Reis; freis@fmed.uc.pt

Received 21 May 2017; Accepted 12 July 2017; Published 27 August 2017

Academic Editor: Kim Connelly

Copyright (C) 2017 Cristina Mega et al. This is an open access article distributed under the Creative Commons Attribution License, which permits unrestricted use, distribution, and reproduction in any medium, provided the original work is properly cited.

\begin{abstract}
Diabetic nephropathy (DN) is now the single commonest cause of end-stage renal disease (ESRD) worldwide and one of the main causes of death in diabetic patients. It is also acknowledged as an independent risk factor for cardiovascular disease (CVD). Since sitagliptin was approved, many studies have been carried out revealing its ability to not only improve metabolic control but also ameliorate dysfunction in various diabetes-targeted organs, especially the kidney, due to putative underlying cytoprotective properties, namely, its antiapoptotic, antioxidant, anti-inflammatory, and antifibrotic properties. Despite overall recommendations, many patients spend a long time well outside the recommended glycaemic range and, therefore, have an increased risk for developing micro- and macrovascular complications. Currently, it is becoming clearer that type 2 diabetes mellitus (T2DM) management must envision not only the improvement in glycaemic control but also, and particularly, the prevention of pancreatic deterioration and the evolution of complications, such as DN. This review aims to provide an overview of the current knowledge in the field of renoprotective actions of sitagliptin, namely, improvement in diabetic dysmetabolism, hemodynamic factors, renal function, diabetic kidney lesions, and cytoprotective properties.
\end{abstract}

\section{Introduction}

Type 2 diabetes mellitus (T2DM) is recognized as being a group of chronic diseases characterized by hyperglycaemia where the importance of protecting the body from excessive glucose circulation cannot be overstated. The central key features of T2DM are a defect in insulin resistance and/or insulin secretion, which lead to hyperglycaemia and disrupt the normal relationship between insulin sensitivity and pancreatic $\beta$-cell function [1]. Degeneration of Langerhans islets with $\beta$-cell loss is secondary to insulin resistance and is regarded as the most important lesion for disease progression [2-5]. Currently, eight central players are considered to be involved in T2DM pathophysiology-the ominous octet-composed by muscle/liver insulin resistance, $\beta$-cell failure, enhanced lipolysis, hyperglucagonaemia, dysregulation of hepatic glucose production, brain insulin resistance, increased renal glucose reabsorption, and incretin hormone [glucagon-like peptide 1 (GLP-1) and glucosedependent insulinotropic polypeptide (GIP)] deficiency, all contributing to a persistent state of hyperglycaemia [6]. GLP-1 and GIP are peptide hormones that are involved in the physiologic regulation of glucose homeostasis. These hormones are secreted from the gastrointestinal tract after a meal and stimulate insulin secretion in a glucose-dependent manner [7]. In T2DM, there is an "incretin defect," manifested through the reduction in incretin bioavailability, which in part is due to their rapid inactivation by dipeptidyl peptidase- 4 (DPP-4) [8]. It is now also acknowledged that biochemical pathways, such as apoptosis, low-grade inflammation, and oxidative stress, which are mainly fuelled by hyperglycaemia and hyperlipidaemia, are key mediators of insulin resistance and $\beta$-cell dysfunction and are involved in the overall aggravation of the diabetic state $[3,9-15]$. The persistent 
dysfunction of these metabolic pathways in the "ominous octet" organs, through the direct and indirect effects of hyperglycaemia, seems to have an important role in the development of T2DM's major long-term complications [16, 17].

Generally, diabetic complications are divided into macrovascular (coronary artery disease, peripheral arterial disease, and stroke) and microvascular complications (nephropathy, retinopathy, and neuropathy). T2DM-induced micro- and macrovascular complications and their pathologies are major contributors to disease morbidity and mortality, respectively $[18,19]$. It is now known that inflammation promotes development and progression of diabetic microangiopathy, which trigger extracellular matrix protein synthesis and capillary basement membrane thickening; these conditions contribute to the development of severe diabetic complications, such as nephropathy, retinopathy, and neuropathy [20-22].

Diabetic nephropathy (DN) originates insidious chronic kidney disease (CKD) and is recognized as the single most common cause of end-stage renal disease (ESRD) and one of the main causes of death in diabetic patients worldwide, being also acknowledged as an independent risk factor for cardiovascular disease (CVD) [23-25].

T2DM can generally be prevented with interventions such as change in dietary habits and physical activity. However, individuals with established diabetes should be treated with antidiabetic drugs $[26,27]$. T2DM therapy has vastly improved in the last 10 years with the availability of new drugs and drug classes. These pharmacological agents improve glycaemic control by increasing insulin secretion, ameliorating insulin action, decreasing hepatic gluconeogenesis, and delaying the absorption of carbohydrates [28, 29]. Currently, T2DM can be managed with biguanides, sulfonylureas, meglitinide derivatives, alpha-glucosidase inhibitors, thiazolidinediones, selective sodium-glucose transporter-2 (SGLT2) inhibitors, insulins, amylinomimetics, bile acid sequestrants, dopamine agonists, and incretin-based therapies, which include glucagon-like peptide1 (GLP-1) agonists and DPP-4 inhibitors, of which sitagliptin was the first to be discovered and marketed [29, 30]. Moreover, these drugs may be used in various therapeutic combinations as an add-on therapy for improved management of hyperglycaemia [29].

Treatment regimens of T2DM that reduce the levels of $\mathrm{HbA} 1 \mathrm{c}$ to near or below $7 \%$ are able to significantly reduce the risk of microvascular complications and diabetes-related death [31-36]. Current recommendations by the consensus of the American Diabetes Association (ADA) and European Association for the Study of Diabetes (EASD) justify the selection of appropriate treatment based on its capability to achieve and maintain desired glycaemic goals [36-38]. Despite all recomendations, many patients spend a long time well outside the target glycaemic range and, therefore, have an increased risk for developing micro- and macrovascular complications $[6,39]$. Currently, it is becoming clearer that T2DM management must envision not only glycaemic control but also and particularly, the mechanisms behind progression of pancreatic deterioration and evolution of diabetic complications [40, 41].

The ground-breaking incretin-based therapies that encompass GLP-1 agonists and DPP-4 inhibitors seem to address a previously unmet need in diabetes by modulating glucose supply $[42,43]$. In fact, DPP-4 inhibitors, and especially sitagliptin, have progressively increased their therapeutic prominence in the management of T2DM by their capability to potentiate incretin activity. Various studies have described many pleiotropic effects of sitagliptin on various organs and tissues. The knowledge that DPP-4 has the highest expression levels in the kidneys of mammals, which is additionally upregulated in DN [44], indicates that DPP-4 inhibition by sitagliptin is a plausible therapeutic target for management of diabetic nephropathy.

This review outlines the evidence found in previous studies regarding the renoprotective action of sitagliptin in $\mathrm{DN}$, focusing on renal function and lesions, as well as kidney tissue cytoprotective properties, particularly its antiapoptotic, antifibrotic, anti-inflammatory, and antioxidant properties.

\section{The Incretin System in Diabetic Nephropathy}

2.1. Overview of DN Pathophysiology. The kidney, besides contributing to the aggravation of hyperglycaemia in T2DM through gluconeogenesis [45] and glucose reabsorption, does not remain unscathed through diabetic evolution, developing progressive lesions and functional impairments that lead to DN [46]. Dysmetabolism, with a central role for chronic hyperglycaemia, and hemodynamic factors, namely, overactivity of the renin-angiotensin-aldosterone system (RAAS) and vascular endothelial growth factor (VEGF) deficiency, have key roles in the pathophysiology of DN. Chronic hyperglycaemia and dyslipidaemia induce mitochondrial deregulation and oxidative stress in kidney cells, which activate several metabolic pathways, including protein kinase $\mathrm{C}$ [47], nonenzymatic glycation [48], oxidative stress [49-54], and inflammation $[55,59]$.

Inflammatory response is mediated by diverse types of inflammatory cells (including macrophages, monocytes, and leukocytes) and molecules (such as adhesion molecules, chemokines, and cytokines, namely, TNF- $\alpha$ and IL- $1 \beta$ ) $[55,60]$. Besides altering glomerular hemodynamics and promoting increased vascular permeability, TNF- $\alpha$ activates several signalling pathways leading to apoptosis and necrosis. IL- $1 \beta$ also modifies vascular permeability and increases the expression of chemokines that induce proliferation and synthesis of extracellular matrix in the mesangium [57]. As inflammation persists, renal tissues are damaged, occurring endothelial dysfunction, mesangial nodule formation (Kimmelstiel-Wilson bodies), renal fibrosis, and apoptosis [55, 60].

Hemodynamic factors $[61,62]$ predominantly mediated by angiotensin II play a role via overactivity of the RAAS and promotion of VEGF deficiency. Interaction of metabolic factors, such as obesity and chronic hyperglycaemia, alters vasoactive regulating mechanisms of afferent and efferent arteriolar tonus, leading to increased glomerular capillary hydrostatic pressure, hyperperfusion, hyperfiltration, and microalbuminuria. These early renal hemodynamic changes, combined with systemic hypertension, are important in the development and progression of renal disease in T2DM [63].

Albuminuria is mostly glomerular in origin, as albumin must cross the glomerular filtration assembly, which is 
composed of three main cellular barriers that are of utmost importance for the ultrafiltration process, the fenestrated glomerular endothelial cells, glomerular basement membrane (GBM), and glomerular epithelial cells or podocytes. Alterations in this three-layered structure, like increased intraglomerular pressure, loss of negatively charged glycosaminoglycans in the basement membrane, and further in disease evolution, and increase in basement membrane pore size, contribute to albuminuria [64]. An increasing number of proteins have been identified to be present in foot projections of podocytes. Nephrin is a zipper-like protein that plays a functional role in the structure of the slit diaphragm. The spaces between the teeth of the zipper allow selective transport of small molecules (such as glucose and water) retaining, however, large proteins. Evidence suggests that nephrin could play a key role in glomerular filtration barrier and development of proteinuria as it is found to be downregulated in kidney failure and in diabetic rats [51]. In diabetes, early flattening and retraction of podocytes' foot processes are associated with thickening of the GBM. Thickening of GBM, as well as accumulation of mesangial matrix, and increased numbers of mesangial cells are considered as initial microscopic abnormalities. As the disease progresses, there is a close relationship between mesangial expansion and declining of glomerular filtration. Mesangial expansion also correlates inversely with capillary filtration surface area, which itself correlates to glomerular filtration rate [64]. Long-term persistence of the previous factors ultimately induces histological abnormalities in glomeruli, tubules, interstitium, and renal vascular tissues, affecting basement membranes, podocytes, endothelial, and mesangial cells, which eventually become irreversible [64-68].

The cumulative presence of cooperative risk factors, namely, obesity, hypertension, insulin resistance, hyperglycaemia, dyslipidaemia, and microalbuminuria, appears to support not only the aggravation of CKD but also the development of CVD called the cardiorenal metabolic syndrome [69]. However, the underlying mechanisms of microand macrovascular complications of diabetes are not yet completely clarified. It seems that diabetic microangiopathy in conjunction with the aforementioned diabetogenic factors, together with neovascularization of vasa vasorum, can lead to macrovascular complications. Consequently, alterations in small arteries and capillaries may be responsible not only for the enduring microvascular complications but also for CVD in diabetes and, thus, may constitute one more link between DN and CVD [18].

2.2. The Role of the Incretin System in the Pathophysiology of $D N$. The presence of the incretin hormone GLP-1 and of its receptor (GLP-1R) in the kidneys suggests that the incretin system can play a role in the modulation of kidney function $[70,71]$. Incretin dynamics, which are significantly altered in T2DM, seem also to be implicated in alteration of vascular tonus, natriuretic, and diuretic properties in the kidney [72]. The localization of GLP-1R in endothelial cells and in the proximal renal tubules plays a role in regulating the composition of urine. Stimulation of the GLP-1R in blood vessels results in relaxation of smooth muscle and increased renal blood flow [73].

In the normal kidney, stimulation of GLP-1R by GLP-1 results in inactivation of the $\mathrm{Na}^{+} / \mathrm{H}^{+}$exchanger isoform 3 (NHE3) transporter, blocking $\mathrm{Na}^{+}$and other electrolytes retrieval from tubular fluid, thus resulting in natriuresis and water loss, and possibly, lowered blood pressure [74]. However, DPP-4 has its highest cellular expression in the kidneys of mammals, being found in the brush border of the proximal tubules, endothelium of the glomerular capillaries, and epithelium of Bowman's capsule [8, 44, 75]. In T2DM, DPP-4 is additionally upregulated in glomeruli of patients with $\mathrm{DN}$, being implicated in the reduction of the half-life of GLP-1 in the kidney $[44,76]$ and altering its natriuretic and diuretic properties [76].

Other pathophysiological interventions by DPP-4 seem to involve its interaction with extracellular matrix proteins in the kidney during the development and evolution of $\mathrm{DN}$, but there is still insufficient data demonstrating that selective DPP-4 inhibition is able to affect these independent interactions [75]. The association between DPP- 4 and integrin $\beta 1$ appears to promote endothelial-to-mesenchymal transition (EndMT) by negatively regulating endothelial viability signalling via suppression of the VEGF-receptor 2 and induction of VEGF-receptor 1 in endothelial cells. It seems that DPP-4 inhibition is capable of inhibiting EndMT and transforming growth factor- $\beta 2$ - (TGF- $\beta 2$-) induced Smad3 phosphorylation, and thus, the progression to renal sclerosis. EndMT is a known contributor to the accumulation of activated fibroblasts and myofibroblasts in kidney fibrosis [77].

Furthermore, DPP- 4 might be implicated in the inactivation of stromal-derived factor-1 alpha (SDF- $1 \alpha$ ), a chemokine linked to the migration of hematopoietic and endothelial progenitor cells (EPCs) to sites of ischemic injury, involved in tissue repair and in the response to tissue hypoxia [44]. It has been reported that DPP-4 inhibition is able to recruit EPCs to sites of [78].

Direct effects of DPP-4 on immune cells and indirect effects through GLP-1-dependent and GLP-1-independent pathways suggest that enzyme inhibition may have beneficial effects beyond glycaemic control, which may contribute to CKD and CVD outcomes [71].

\section{Sitagliptin}

3.1. Pharmacokinetic and Pharmacodynamic Properties of Sitagliptin. Sitagliptin is an oral antidiabetic drug with a recommended dose of $100 \mathrm{mg}$ once a day. Oral absorption is not affected by food. Sitagliptin displays $87 \%$ of bioavailability and a reversible fraction bound to plasma proteins of $38 \%$ [79]; its half-life is around 12.4 hours; hepatic metabolism of sitagliptin is minimal, mainly by cytochrome P450 3A4, while excretion occurs mainly $(70-80 \%)$ by the kidney in its unchanged form, with a renal clearance of approximately $350 \mathrm{ml} / \mathrm{min}$ [80]. In general, the pharmacokinetic profile of sitagliptin is similar in both healthy volunteers and T2DM patients. The pharmacokinetic properties of the drug have also been evaluated in special patient populations with varying grades of hepatic and renal dysfunction. As a result of its 
metabolism and elimination route, dose adjustment is only required in patients with severe renal insufficiency, being effective and safe in patients with mild/moderate renal or hepatic impairment [81-85]. No dosage adjustment is necessary related to age, gender and race, or body mass index. Sitagliptin also has a low propensity for pharmacokinetic drug interactions [7].

Sitagliptin is a potent and highly selective DPP-4 competitive inhibitor that does not affect the closely related enzymes DPP-8 or DPP-9 at therapeutic concentrations [75-86]. Sitagliptin acts by inhibiting over $80 \%$ of the activity of DPP-4 enzyme (at $12 \mathrm{~h}$ postdose for $50 \mathrm{mg} /$ day and at $24 \mathrm{~h}$ postdose for $\geq 100 \mathrm{mg} /$ day), which is responsible for degrading GLP-1, preventing therefore its inactivation. This increases and prolongs plasma concentrations of the active form of GLP-1, allowing the consequent stimulation of insulin synthesis and secretion from pancreatic $\beta$-cells in a glucose-dependent manner [87-90].

As T2DM patients exhibit relative resistance to the actions of GIP [91], the main goals of DPP-4 inhibitors are to prolong the beneficial effects of endogenous GLP-1 [92] in order to maintain its insulinotropic activity [93]. Glycaemic levels are then further regulated by the resulting higher insulin levels and glucagon suppression from the direct action of GLP-1 on pancreatic $\alpha$-cells [94]. Sitagliptin reduces blood glucose levels, in either the postprandial or the fasting state. It works differently from the previous drugs available for diabetes treatment and is orally active $[95,96]$.

Clinical trials have demonstrated the efficacy of sitagliptin in terms of improving glycaemic control in T2DM patients, used as either monotherapy, initial combination therapy (usually with a fixed dose combination of sitagliptin/metformin) or add-on therapy to metformin or to other antihyperglycaemic drugs, with or without metformin. Sitagliptin showed efficacy in decreasing HbAlc, fasting plasma glucose (FPG), and postprandial plasma glucose (PPG) levels and also increasing the proportion of patients achieving target HbA1c levels $(<7.0 \%)$, as shown in several clinical studies [79, 97-100].

3.2. Sitagliptin Affords Protection in Organs Targeted by Diabetes. Experimental studies performed in animal models of T2DM that were treated with sitagliptin showed remarkable beneficial effects on glucose and HbA1c levels, an improvement of insulin resistance, together with promotion of weight loss and amelioration of lipid profile [101-110]. Moreover, sitagliptin was able to consistently alleviate oxidative stress and inflammation, which are key players in diabetes pathophysiology and in the development of DN [51, 57, 103, 111].

Sitagliptin promotes a conjoined improvement in dyslipidaemia and hypertension, which are interactive factors for CKD and CVD [104, 107-111]. Sitagliptin attenuates the progress of atherosclerosis in apolipoprotein-E-knockout mice via AMPK- and MAPK-dependent mechanisms [110]. Several reports have corroborated the cardiovascular protective aspects and have also identified cytoprotective properties, such as a decrease in heart oxidative stress, inflammation, and apoptosis [19, 78, 103, 112-118].
Concerning the impact of sitagliptin on lipid profiles in T2DM patients, the majority of studies reported a beneficial effect on triglycerides (TGs), high-density lipoprotein cholesterol (HDL-c), and low-density lipoprotein cholesterol (LDL-c) $[119,120]$. DPP-4 inhibition also appears to improve endothelial function in diabetic patients, in both a GLP-1-dependent and GLP-1-independent manner $[121,122]$. Furthermore, sitagliptin was able to increase EPC levels in diabetic patients [78].

Our research group has extensively studied the protective effects of sitagliptin on various organs targeted by diabetes, namely, the pancreas, retina, and kidney, in an animal model of T2DM. Sitagliptin was able to prevent the aggravation of both endocrine and exocrine pancreatic histopathological lesions and presented antiapoptotic and anti-inflammatory properties, as well as decreased insulin resistance and proproliferative and angiogenic actions $[103,123]$. In the retina, sitagliptin treatment prevented changes in the endothelial subcellular distribution of tight junction proteins and improved nitrosative stress and inflammatory and apoptotic states [124]. Later studies in type 1 diabetic rats revealed that sitagliptin could prevent the increase in blood-retinal barrier permeability and decrease the retinal inflammation state and neuronal apoptosis [125]. Our studies in the kidney also revealed protective properties $[8,126]$. Other authors have also found diabetic lesion improvement in the pancreas associated to antiapoptotic, pro-proliferative [111, 127-131], and anti-inflammatory properties [132-134].

Besides decreasing insulin resistance $[5,135,136]$ and improving hepatic insulin sensitivity, sitagliptin seems also to prevent steatosis [137] through GLP-1R signalling in the liver and reduction of endoplasmic reticulum stress [138]. GLP-1R has been found to be expressed in human hepatocytes [138]. However, other authors failed to detect GLP-1R mRNA transcripts in human, rat, or mouse liver [139]. Antiapoptotic effects on human hepatoma cells by DPP-4 inhibition have also been identified [140].

Treatment of nonobese diabetic mice with sitagliptin not only prevented linoleic acid-induced adipose tissue hypertrophy but also protected against adipose tissue inflammation [131, 137].

In T2DM rats with uncontrolled neuropathy, sitagliptin as add-on to insulin therapy produced neuroprotective effects and ameliorated hyperalgesia, oxidative stress, and inflammation, more than either drug alone [141].

\section{Sitagliptin Affords Renoprotection in Diabetic Nephropathy}

4.1. Effects of Sitagliptin on Renal Function. The effects of sitagliptin on DN, using the ZDF rat, noticeably reduced renal dysfunction and injury in this model. In fact, sitagliptin treatment was able to decrease blood urea nitrogen (BUN) levels to values identical to those observed in lean control rats, suggesting an amelioration of renal function [126]. Nevertheless, serum creatinine levels were unchanged between study groups, which are in accordance with others using the ZDF rat as an animal model $[106,142]$. 
Direct vasodilator effects have also been described for DPP-4 inhibitors [143]. In this regard, interactions of angiotensin II and DPP-4/GLP-1 signalling have been proposed as one of the mechanisms for the blood pressure- (BP-) lowering effect of DPP-4 inhibition [144]. Sitagliptin seems to be able to lower BP in a GLP-1dependent manner through GLP-1R localized in renal endothelial cells and in the proximal renal tubules, which play a role in regulating the composition of urine. DPP-4 inhibition by sitagliptin administration increases GLP-1 availability which stimulates GLP-1R in blood vessels, through the sequential activation of the PKA/LKB1/ AMPK $\alpha /$ eNOS axis, thus inducing relaxation of smooth muscle and improvement of renal blood flow [143, 145].

There are solid evidences that the proximal tubules play a major role in microalbuminuria in $\mathrm{DN}$, namely, in early stages of the disease $[146,147]$. In addition, stimulation of GLP-1R in the proximal tubules results in increased loss of salt, water, and electrolytes in urine. The latter occurs as the GLP-1Rs situated in proximal convoluted tubules of the kidneys are functionally linked to NHE3 transporters. NHE3 promotes recovery of $\mathrm{Na}^{+}$and other electrolytes from the tubular fluid (and thus from urine), thereby returning them into the circulation. Activation of the GLP-1R by GLP-1 results in inactivation of NHE3, which leads to increased $\mathrm{Na}^{+}$loss in urine, consequentially, through osmotic effects, to increased fluid loss, and possibly, to lowered BP [74]. An association of NHE3 with DPP-4 was found in the proximal tubule, which might affect NHE3 surface expression and/or activity [148]. Furthermore, DPP-4 inhibition, in experimental models of obesity and heart failure, was able to upregulate megalin, a receptor that mediates endocytosis of proteins in the proximal tubule $[149,150]$. DPP-4 inhibition improved kidney injury and proteinuria in obese rodent models [126, 150-152]. Consistently, Aroor et al. have demonstrated that increased DPP-4 activity, evoked by angiotensin II, suppresses megalin expression in mice, an effect that was partially abolished by using a DPP4 inhibitor [153].

Effects of GLP-1 on lowering BP have been reported in both animal and human studies $[154,155]$. The natriuretic and diuretic properties of GLP-1 were proved in infusion studies in a rat model of salt sensitivity by chronic intravenous infusion of GLP-1 [72]. Although glycaemic levels affect renal pathophysiology, the previously mentioned effects of incretin protection appear to be independent of these levels, although the underlying mechanisms still remain to be clarified [156, 157]. Diuretic and natriuretic actions of DPP-4 inhibitors seem to offer renoprotection in the setting of hypertension and other disorders of sodium retention. However, in the case of sitagliptin, available data is not yet sufficient to confirm this protective effect $[74,76]$.

4.2. Effects of Sitagliptin on Renal Lesions. Although DN has been traditionally considered primarily a glomerular disease, it is now widely accepted that the rate of function deterioration correlates best with the degree of renal tubulointerstitial fibrosis. This suggests that although the primary event is a condition marked by glomerular changes resulting in proteinuria, the long-term outcome is determined by events in the renal interstitium $[158,159]$.

In preclinical studies, initial histopathological observations of DN focused mainly on glomerular lesions, alluding, only briefly, to tubulointerstitial lesions and considering their presence as a secondary lesion of $\mathrm{DN}[160,161]$. The description of vascular lesions in the kidney was absent in animal model studies and could be scarcely found in a few human DN reports. Thus envisioning evaluation conformity and better correlation between human nephropathy and renal lesions observed in animal models, the international histopathological classification, currently approved for human DN, should be adopted in these studies. This histological classification was established in 2010 and evaluates glomerular, tubulointerstitial, and vascular lesions in a semiquantitative manner, according to their severity and tissue distribution [162].

In experimental animal models, diabetic glomerular lesions initially display thickening of the GBM and mesangial expansion, which are followed by the appearance of nodular sclerosis and vascular pole hyalinization, accompanied by glomerular hypertrophy. With disease aggravation, glomerulosclerosis and glomerular atrophy become evident (Figure 1(a)), confirming the link between diabetes (hyperglycaemia and hyperlipidaemia) and progressive renal injury $[8,126]$.

In the tubulointerstitium (Figure 1(a)), tubular hypertrophy and associated basement membrane alterations (thickening and irregularity) precede interstitial fibrosis, tubular atrophy (IFTA), and formation of hyaline cylinders, which accompany progressive renal dysfunction (Figure 1(a)). There seems to be a correlation between aggravation of tubulointerstitial and glomerular lesions, which is suggested by the aggravation of both glomeruli and interstitium [126]. Interstitial enlargement also correlates with glomerular filtration, albuminuria, and mesangial expansion. It has been suggested that the accumulation of protein in the cytoplasm of proximal tubular cells causes an inflammatory reaction which leads to tubulointerstitial lesions [64, 163].

Arteriolar hyalinosis and arteriosclerosis are the main vascular lesions found in human $\mathrm{DN}$ and also in some experimental animal models of diabetes (Figure 2(a)), and similarly, also aggravate with disease progression $[126,162]$. Various studies have shown that DPP-4 inhibition is able to improve renal lesions in experimental animal models. In fact, in the obese diabetic ZDF rat, sitagliptin treatment ameliorated glomerular, tubulointerstitial (Figure 1(b)), and vascular lesions (Figure 2(b)) [126]. Other studies have also reported that suppression of DPP-4 activity and/or protein expression resulted in an amelioration of kidney fibrosis, which was correlated with inhibition of EndMT and reduction of inflammatory and fibrotic markers [164-166]. Similar histopathological improvements with incretin therapies have been disclosed by other studies [166-168].

4.3. Renal Cytoprotective Effects of Sitagliptin. Several authors have been postulating that gliptins could theoretically avoid or delay diabetic complications [40, 169-170], namely, 


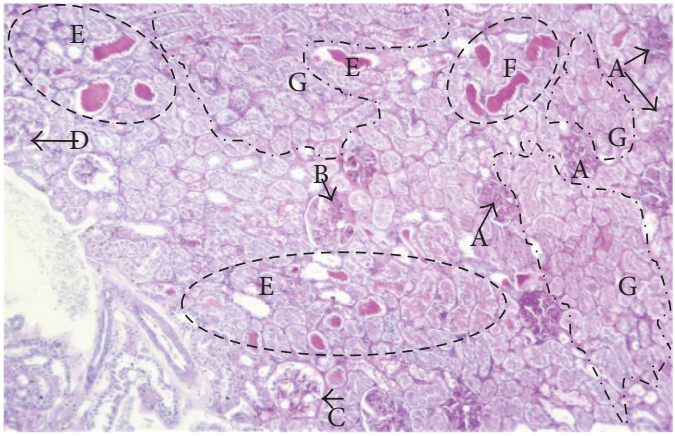

(a)

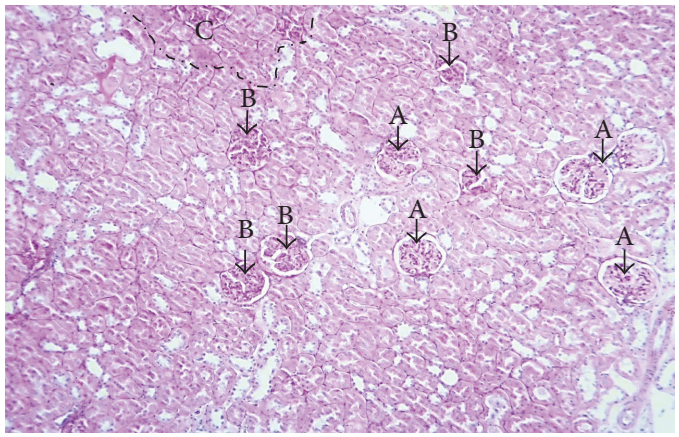

(b)

FIgURE 1: Effects of sitagliptin treatment on diabetic nephropathy lesions in an experimental model of type 2 diabetes. (a) Histopathological lesions in untreated diabetic nephropathy. Glomerular lesions: (A) glomerulosclerosis, (B) nodular sclerosis, (C) thickened capsule of Bowman, and (D) normal glomerulus. All other glomeruli on the image display various degrees of mesangial expansion. Tubulointerstitial lesions: (E) hyaline cylinders, (F) irregular shape of hyaline cylinders that indicates irregular tubular membranes, $(G)$ various degrees of thickened and irregular tubular basement membranes a characteristic of interstitial fibrosis and tubular atrophy (IFTA). PAS staining of a kidney section from an obese diabetic untreated ZDF rat (original magnification $\times 100$ ). (b) Improvement of histopathological lesions in sitagliptin-treated diabetic nephropathy. Glomerular lesions: Reduction of lesion severity, with global rise in (A) normal glomeruli and (B) the remainder showing various degrees of mesangial expansion, an early lesion of disease. Tubulointerstitial lesions: Most of the interstitium has normal appearance, showing only a focal patch of moderate interstitial fibrosis and tubular atrophy (IFTA); PAS staining of a kidney section from an obese diabetic sitagliptin-treated ZDF rat (original magnification $\times 100$ ).

due to reduction of oxidative stress and inflammation, as well as by antiapoptotic and pro-proliferative properties on various organs and tissues, including the kidney [101-103, 138, 171, 172].

Considering that sitagliptin is not able to completely normalize hyperglycaemia in studies using low doses $[8,103,126]$, an alternative mechanism for the beneficial effect on kidney function/lesions can occur by a direct tissue DPP-4 inhibition, via GLP-1-dependent and/or GLP-1independent pathways. The GLP-1-dependent activity is reinforced by the expression of GLP-1R in the kidney. In fact, there are several mechanisms by which direct renoprotection

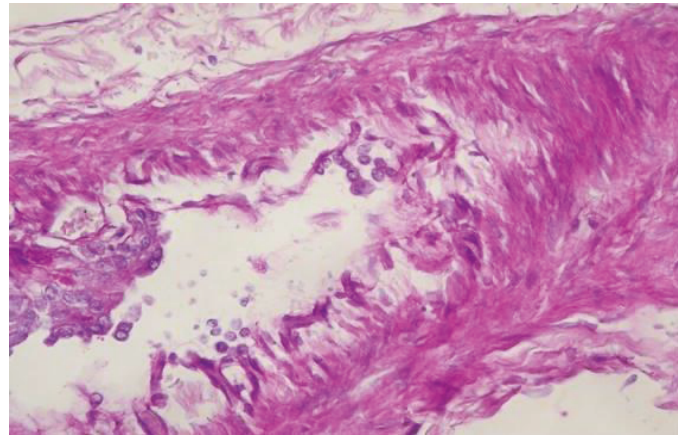

(a)

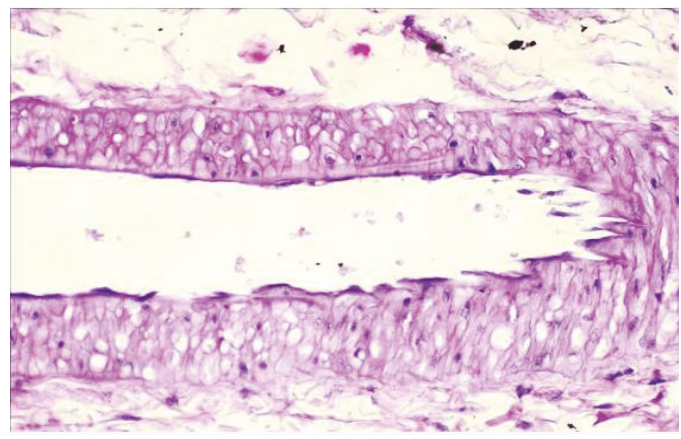

(b)

FIGURE 2: Effects of sitagliptin treatment on diabetic nephropathy vascular lesions in an experimental model of type 2 diabetes. (a) Histopathological lesions in untreated diabetic nephropathy: Renal arteries exhibiting marked hyperplastic arteriosclerosis and thickening and detachment of the intimal layer. Endothelial cells can no longer be identified; PAS staining of a kidney section from an obese diabetic untreated ZDF rat (original magnification $\times 400$ ). (b) Improvement of histopathological vascular lesions in sitagliptin-treated diabetic nephropathy: A marked reduction in total wall and intimal layer thickening, showing normal endothelial cells; PAS staining of a kidney section from an obese diabetic sitagliptin-treated ZDF rat (original magnification $\times 400$ ).

could occur. GLP-1 has been associated with the protection of mesangial cells, as well as with the reestablishment of $\mathrm{Na}^{+}$, acid-base and fluid homeostasis, which contributes to BP lowering and, collectively, to renoprotection [173-175]. The GLP-1-independent effects have been associated with other known substrates of DPP-4, such as high mobility group box 1 protein (HMGB1), meprin $\beta$, neuropeptide $Y$ (NPY), and peptide YY (PYY) $[76,164]$.

It is known that DPP-4 exhibits its enzymatic activity in both membrane-anchored cell-surface peptidase and as a smaller soluble form in blood plasma [77, 131, 176]. In fact, there are some studies suggesting that microvascular endothelial cells are the main sources of endogenous DPP-4 [177, 178]. In addition, in vitro studies showed that both DPP-4 mRNA expression and enzyme activity were enhanced by exposure of human glomerular endothelial cells to high glucose concentrations [179-181]. In agreement, our research group has recently demonstrated that diabetic rats present an increased protein expression of DPP-4 in the kidney, when compared to nondiabetic animals [8]. 
Experimental studies in ZDF rats showed that chronic hyperglycaemia is associated with increased proinflammatory cytokines, namely, IL-1 $\beta$ and TNF- $\alpha$ in the kidney [8]. These outcomes are corroborated by other authors that described an increased expression of those proinflammatory cytokines in the diabetic kidney [58, 77, 182], leading to enhanced vascular permeability, oxidative stress, renal hypertrophy, and tubulointerstitial lesions. DPP-4 inhibition by low-dose sitagliptin has prevented the inflammatory profile and the proapoptotic state observed in the diabetic rat kidney, which might justify the improvement in renal function and tissular lesions (glomerular, tubulointerstitial, and vascular lesions). In fact, sitagliptin was able to prevent the increase in both mRNA and protein levels of the proinflammatory cytokines IL- $1 \beta$ and TNF- $\alpha$ in the diabetic kidneys of ZDF rats [8].

In Wistar rats treated with low- or high-dose sitagliptin during 16 weeks, urinary albumin excretion rate (UAER), serum creatinine, and kidney hypertrophy were significantly decreased. However, creatinine clearance rate and active GLP-1 levels were increased, with more pronounced changes in the high-dose sitagliptin-treated animals. Glomerular lesions were also improved following sitagliptin treatment. Protein and mRNA expression levels of podocalyxin and GLP-1R were significantly increased in both groups, while expression of signal-regulated kinases $1 / 2$ (ERK1/2) and transforming growth factor- $\beta 1$ (TGF- $\beta 1$ ) was decreased [183]. Podocalyxin is a negatively charged transmembrane glycosaminoglycan that covers the secondary foot processes of the podocytes, which by electrical repellence keeps adjacent foot processes separated, maintaining the urinary filtration barrier open. Podocalyxin depletion is inversely correlated to albuminuria $[64,184]$. These overall results also confirm a delay in DN progression promoted by sitagliptin, possibly via the inhibition of ERK1/2 signalling which seems to be activated by AGEs and is implicated in epithelialmyofibroblast transition [185]; by decreased TGF- $\beta 1$ expression, a cytokine associated with inflammatory responses in T2DM, which has been recognized to be involved in the development of glomerulosclerosis and interstitial fibrosis; and by increasing the interaction between GLP-1 and the GLP-1R [186].

Recently, in a study involving $164 \mathrm{DN}$ patients treated with metformin, sitagliptin (100 mg, once a day) was able to decrease UAER, which presented a close correlation with markers of renal fibrosis: TGF- $\beta 1$ and platelet-derived growth factor-BB (PDGF-BB) [187]. Furthermore, PDGF$\mathrm{BB}$ mRNA has been found to be overexpressed in diabetic patients and is considered a factor for mesangial cell proliferation and induction of TGF- $\beta 1$, which shows a profibrotic action, being involved in the development of renal hypertrophy and accumulation of extracellular matrix in DN [188]. In addition, DPP-4 inhibition is known to downregulate TGF$\beta 1$ expression in mesangial cells [189]. Li et al. [190] suggest that the renoprotective mechanism of sitagliptin may be due to a reduction in protein kinase $\mathrm{B}$ ( $\mathrm{PKB}$ )/Akt levels, which are involved in apoptosis pathways and restoration of adenosine monophosphate-activated protein kinase (AMPK) activity in diverse physiological processes, including ion transport, podocyte function and cell growth and cellular energy homeostasis, inhibition of TGF- $\beta 1$, fibronectin, and p38/ERK MAPK signalling pathways involved in the regulation of ECM expression.

The activation of signalling pathways linked to cell death resulting from chronic hyperglycaemia and to a state of low-grade chronic inflammation contributes to an increase in apoptosis. A proapoptotic state seems to be favoured in the kidney of diabetic ZDF rats, which appears to be mediated by Bax and Bid. Sitagliptin prevented the Bax to $\mathrm{Bcl}-2$ (mRNA and protein) ratio increase and reversed the increase in Bid and TUNEL-positive cells induced by chronic hyperglycaemia in the kidneys of this animal model [8]. In addition, sitagliptin was able to ameliorate serum TG content, thus reducing lipotoxicity-evoked apoptosis in the kidney [8, 190-193].

Additionally, it has been demonstrated that glucoseinduced ROS production initiates podocyte apoptosis and its depletion in vitro and in vivo, leading to DN $[49,56$, 194]. Therefore, the reduction of oxidative stress afforded by sitagliptin could eventually reduce ROS production and the consequent risk of cell death. A study on renal ischemia reperfusion damage in diabetic rats found sitagliptin to significantly decrease lipid peroxidation, xanthine oxidase activity, myeloperoxidase activity, and nitric oxide levels in renal tissue in comparison to those in untreated rats. Antioxidant enzymes like glutathione, glutathione peroxidase, superoxide dismutase, and catalase were significantly increased in sitagliptin-treated diabetic rats compared to those in the nontreated ones [195]. Other studies have demonstrated that GLP-1 receptor activation has also attenuated diabetic renal injury by reduction of kidney oxidative stress, inflammation, and apoptosis [196-199].

\section{Concluding Remarks}

The innovative class of DPP-4 inhibitors, such as sitagliptin, seem to address previously unmet needs in diabetes. In fact, DPP-4 has the highest expression levels in the kidneys of mammals, which is additionally upregulated in diabeticinduced CKD, indicating that DPP-4 inhibition by sitagliptin is a plausible therapeutic target for management of DN. In fact, several studies have been describing putative pleiotropic effects of sitagliptin on various organs and tissues. Sitagliptin showed not only the capacity to ameliorate diabetic dysmetabolism but also the potential to avert the decline of insulin secretion ability in pancreatic beta-cells through cytoprotective properties; these effects suggest a role in prevention of T2DM evolution and its complications. In the kidney, sitagliptin seems to provide renoprotection by restoring GLP-1 diuretic and natriuretic actions and by other mechanisms, including antiapoptotic, antifibrotic, anti-inflammatory, and antioxidant effects. However, additional studies are needed to clarify whether sitagliptin acts through indirect action via insulin secretion increment or through direct tissular DPP-4 inhibition. In addition, further research should also elucidate the contribution of GLP-1-dependent (which is sustained by expression of DPP-4 and GLP-1R 
in renal tissues) and/or GLP-1-independent pathways (reinforced by the existence of multiple DPP-4 substrates).

Due to its unique mechanism of action and pharmacological properties, DPP-4 inhibitors (including sitagliptin) have conquered their place in T2DM management. In addition, the low potential for interactions with other antidiabetic drugs allows its use in different combinations, with a low risk of hypoglycaemiac episodes. A fixed-dose combination with sodium/glucose cotransporter 2 (SLGT2) inhibitor ertugliflozin has been recently accepted and seems to contain the potential to exert further beneficial effects on the kidney, as both classes have been reported to lower UAER. Additional positive effects could be expected from the complementary mechanism of action of these drugs, with impact on both renal and cardiovascular systems. Disclosure of its protective actions on the diabetic kidney could open up the possibility of using sitagliptin therapy as a renoprotective strategy against the development and/or delay of DN.

\section{Conflicts of Interest}

The authors declare no conflicts of interest.

\section{Authors' Contributions}

Cristina Mega prepared the manuscript. Edite TeixeiraLemos, Rosa Fernandes, and Flávio Reis equally contributed to the work and are colast authors and coresponsible for the manuscript. All authors read and approved the final manuscript.

\section{Acknowledgments}

The authors gratefully acknowledge the Portuguese Foundation for Science and Technology (FCT) through the projects PEst-C/SAU/UI3282/2013, CNC.IBILI Strategic Project (2015-UID/NEU/04539/2013), and the Operational Programme Competitiveness Factors (COMPETE-FEDER): FCOMP-01-0124-FEDER-028417 and POCI-01-0145-FEDER007440, as well as Centro 2020 Regional Operational Programmes (CENTRO-01-0145-FEDER-000012: HealthyAging2020 and CENTRO-01-0145-FEDER-000008: BrainHealth 2020). Cristina Mega also thanks PROTEC grant by the Polytechnic Institute of Viseu (IPV) (PROTEC-SFRH/ $\mathrm{BD} / 50139 / 2009)$.

\section{References}

[1] M. Virally, J. F. Blicklé, J. Girard, S. Halimi, D. Simon, and P. J. Guillausseau, “Type 2 diabetes mellitus: epidemiology, pathophysiology, unmet needs and therapeutical perspectives," Diabetic Medicine, vol. 33, pp. 231-244, 2007.

[2] S. E. Kahn, "The importance of the $\beta$-cell in the pathogenesis of type 2 diabetes mellitus," American Journal of Medicine, vol. 108, pp. 2S-8S, 2000.

[3] P. Marchetti, R. Lupi, S. D. Guerra, M. Bugliani, L. Marselli, and U. Boggi, "The $\beta$-cell in human type 2 diabetes," Advances in Experimental Medicine and Biology, vol. 654, pp. 501-514, 2010.
[4] M. E. Cerf, "Beta cell dysfunction and insulin resistance," Frontiers in Endocrinology, vol. 4, p. 37, 2013.

[5] S. Yagihashi, W. Inaba, and H. Mizukami, "Dynamic pathology of islet endocrine cells in type 2 diabetes: b-cell growth, death, regeneration and their clinical implications," Journal of Diabetes Investigation, vol. 7, pp. 155-165, 2016.

[6] R. A. D. Fronzo, "From the triumvirate to the ominous octet: a new paradigm for the treatment of type 2 diabetes mellitus (banting lecture)," Diabetes, vol. 58, pp. 773-795, 2009.

[7] D. J. Drucker, "The biology of incretin hormones," Cell Metabolism, vol. 3, no. 3, pp. 153-165, 2006.

[8] C. Marques, C. Mega, A. Gonçalves et al., "Sitagliptin prevents inflammation and apoptotic cell death in the kidney of type 2 diabetic animals," Mediators of Inflammation, vol. 2014, Article ID 538737, 15 pages, 2014.

[9] M. K. Piya, P. G. McTernan, and S. Kumar, "Adipokine inflammation and insulin resistance: the role of glucose, lipids and endotoxin," Journal of Endocrinology, vol. 216, pp. T1-T15, 2013.

[10] S. Guo, "Insulin signaling, resistance, and metabolic syndrome: insights from mouse models into disease mechanisms," Journal of Endocrinology, vol. 220, pp. T1-T23, 2014.

[11] U. J. Jung and M.-S. Choi, "Obesity and its metabolic complications: the role of adipokines and the relationship between obesity, inflammation, insulin resistance, dyslipidemia and nonalcoholic fatty liver disease," International Journal of Molecular Sciences, vol. 15, no. 4, pp. 61846223, 2014.

[12] S. L. Lay, G. Simard, M. C. Martinez, and R. Andriantsitohaina, "Oxidative stress and metabolic pathologies: from an adipocentric point of view," Oxidative Medicine and Cellular Longevity, vol. 2014, Article ID 908539, 18 pages, 2014.

[13] L. Chen, R. Chen, H. Wang, and F. Liang, "Mechanisms linking inflammation to insulin resistance," International Journal of Endocrinology, vol. 2015, Article ID 508409, 9 pages, 2015.

[14] S. Tangvarasittichai, "Oxidative stress, insulin resistance, dyslipidemia and type 2 diabetes mellitus," World Journal of Diabetes, vol. 6, no. 3, pp. 456-480, 2015.

[15] K. N. Keane, V. F. Cruzat, R. Carlessi, P. I. H. de Bittencourt, and P. Newsholme, "Molecular events linking oxidative stress and inflammation to insulin resistance and $\beta$-cell dysfunction," Oxidative Medicine and Cellular Longevity, vol. 2015, Article ID 181643, 15 pages, 2015.

[16] E. J. Bae, "DPP-4 inhibitors in diabetic complications: role of DPP-4 beyond glucose control," Archives of Pharmacal Research, vol. 39, no. 8, pp. 1114-1128, 2016.

[17] L. A. Filla and J. L. Edwards, "Metabolomics in diabetic complications," Molecular BioSystems, vol. 12, pp. 10901105, 2016.

[18] A. Chawla, R. Chawla, and S. Jaggi, "Microvasular and macrovascular complications in diabetes mellitus: distinct or continuum?," Indian Journal of Endocrinology and Metabolism, vol. 20, no. 4, pp. 546-551, 2016.

[19] A. Mima, "Incretin-based therapy for prevention of diabetic vascular complications," Journal of Diabetes Research, vol. 2016, Article ID 1379274, 12 pages, 2016.

[20] T. S. Kern, "Contributions of inflammatory processes to the development of the early stages of diabetic retinopathy," Journal of Diabetes Research, vol. 2007, Article ID 95103, 14 pages, 2007. 
[21] J. F. Navarro-González and C. Mora-Fernández, "The role of inflammatory cytokines in diabetic nephropathy," Journal of the American Society of Nephrology, vol. 19, pp. 433-442, 2008.

[22] A. M. Vincent, B. C. Callaghan, A. L. Smith, and E. L. Feldman, "Diabetic neuropathy: cellular mechanisms as therapeutic targets," Nature Reviews Neurology, vol. 7, pp. 573-583, 2011.

[23] M. Narres, H. Claessen, S. Droste et al., "The incidence of end-stage renal disease in the diabetic (compared to the non-diabetic) population: a systematic review," PLoS One, vol. 11, no. 1, article e0147329, 2016.

[24] J. A. J. G. Van den Brand, "Diabetes mellitus as a cause of end-stage renal disease in Europe: signs of improvement," Clinical Kidney Journal, vol. 9, no. 3, pp. 454-456, 2016.

[25] American Diabetes Association, "Standards of medical care in diabetes-2017," Diabetes Care, vol. 40, Supplement 1, 2017.

[26] M. Y. Donath, D. M. Schumann, M. Faulenbach, H. Ellingsgaard, A. Perren, and J. A. Ehses, "Islet inflammation in type 2 diabetes: from metabolic stress to therapy," Diabetes Care, vol. 31, no. 2, pp. S161-S164, 2008.

[27] W. J. Rejeski, E. H. Ip, A. G. Bertoni et al., "Lifestyle change and mobility in obese adults with type 2 diabetes," New England Journal of Medicine, vol. 366, no. 13, pp. 12091217, 2012.

[28] J. J. Marín-Peñalver, I. Martín-Timón, C. Sevillano-Collantes, and F. J. del Cañizo-Gómez, "Update on the treatment of type 2 diabetes mellitus," World Journal of Diabetes, vol. 7, no. 17, pp. 354-395, 2016.

[29] R. Khardori, "Type 2 diabetes mellitus medication," Medscape, May 2017, http://emedicine.medscape.com/article/ 117853-overview.

[30] R. Godinho, C. Mega, E. Teixeira-de-Lemos et al., "The place of dipeptidyl peptidase- 4 inhibitors in type 2 diabetes therapeutics: a "me too" or "the special one" antidiabetic class?," Journal of Diabetes Research, vol. 2015, Article ID 806979, 28 pages, 2015.

[31] "International Diabetes Federation (IDF) 2014," https://www. idf.org/about-diabetes/what-is-diabetes.

[32] D. M. Nathan, P. McGee, M. W. Steffes, J. M. Lachin, and DCCT/EDIC Research Group, "Relationship of glycated albumin to blood glucose and $\mathrm{HbAlc}$ values and to retinopathy, nephropathy, and cardiovascular outcomes in the DCCT/EDIC study," Diabetes, vol. 63, pp. 282-290, 2014.

[33] National Institute for Health and Care Excellence (NICE), "Type 2 diabetes in adults: management. NICE guidelines [NG28] 2015," April 2017, https://www.nice.org.uk/ guidance/ng28/chapter/1-recommendations.

[34] American Diabetes Association (ADA), "Strategies for Improving Care," Diabetes Care, vol. 39, Supplement 1, pp. S6-S12, 2016.

[35] S. Ayadurai, H. L. Hattingh, L. B. G. Tee, and S. N. Md Said, "A narrative review of diabetes intervention studies to explore diabetes care opportunities for pharmacists," Journal of Diabetes Research, vol. 2016, Article ID 5897452, 11 pages, 2016.

[36] G. Rayman, "Glycaemic control, glucose variability and the triangle of diabetes care," British Journal of Diabetes, vol. 16, Supplement 1, pp. S3-S6, 2016.

[37] S. E. Kahn, M. E. Cooper, and S. D. Prato, "Pathophysiology and treatment of type 2 diabetes: perspectives on the past, present, and future," The Lancet, vol. 383, pp. 1068-1083, 2014.
[38] S. E. Inzucchi, R. M. Bergenstal, J. B. Buse et al., "Management of hyperglycemia in type 2 diabetes: a patientcentered approach: position statement of the American Diabetes Association (ADA) and the European Association for the Study of Diabetes (EASD)," Diabetes Care, vol. 35, no. 6, pp. 1364-1379, 2012.

[39] M. Mata-Cases, D. Mauricio, and J. Franch-Nadal, "Clinical characteristics of type 2 diabetic patients on basal insulin therapy with adequate fasting glucose control who do not achieve HbA1c targets," Journal of Diabetes, vol. 9, no. 1, pp. 34-44, 2017.

[40] D. Russell-Jones and S. Gough, "Recent advances in incretinbased therapies," Clinical Endocrinology, vol. 77, no. 4, pp. 489-499, 2012.

[41] B. L. Wajchenberg, " $\beta$-cell failure in diabetes and preservation by clinical treatment," Endocrine Reviews, vol. 28, no. 2, pp. 187-218, 2017.

[42] W. T. Cefalu, "The physiologic role of incretin hormones: clinical applications," Journal of the American Osteopathic Association, vol. 110, no. 3, Supplement 2, pp. S8-S14, 2010.

[43] M. C. Riddle, "Glycemic management of type 2 diabetes: an emerging strategy with oral agents, insulins, and combinations," Endocrinology and Metabolism Clinics of North America, vol. 34, pp. 77-98, 2005.

[44] A. A. Hasan and B. Hocher, "Role of soluble and membrane-bound dipeptidylpeptidase- 4 in diabetic nephropathy," Journal of Molecular Endocrinology, vol. 59, no. 1, pp. R1-R10, 2017.

[45] J. E. Gerich, "Role of the kidney in normal glucose homeostasis and in the hyperglycaemia of diabetes mellitus: therapeutic implications," Diabetic Medicine, vol. 27, no. 2, pp. 136-142, 2010.

[46] M. A. Nauck, "Update on developments with SGLT2 inhibitors in the management of type 2 diabetes," Drug Design Development and Therapy, vol. 8, pp. 1335-1380, 2014.

[47] H. Noh and G. L. King, "The role of protein kinase C activation in diabetic nephropathy," Kidney International, vol. 106, pp. S49-S53, 2007.

[48] N. Tanji, G. S. Markowitz, C. Fu et al., "Expression of advanced glycation end products and their cellular receptor RAGE in diabetic nephropathy and nondiabetic renal disease," Journal of the American Society of Nephrology, vol. 11, no. 9, pp. 1656-1666, 2000.

[49] K. Susztak, A. C. Raff, M. Schiffer, and E. P. Böttinger, "Glucose-induced reactive oxygen species cause apoptosis of podocytes and podocyte depletion at the onset of diabetic nephropathy," Diabetes, vol. 55, no. 1, pp. 225-233, 2006.

[50] J. M. Forbes, M. T. Coughlan, and M. E. Cooper, "Oxidative stress as a major culprit in kidney disease in diabetes," Diabetes, vol. 57, no. 6, pp. 1446-1454, 2008.

[51] Z. Cao and M. E. Cooper, "Pathogenesis of diabetic nephropathy," Journal of Diabetes Investigation, vol. 2, no. 4, pp. $243-$ 247, 2011.

[52] D. K. Singh, P. Winocour, and K. Farrington, "Oxidative stress in early diabetic nephropathy: fueling the fire," Nature Reviews Endocrinology, vol. 7, no. 3, pp. 176-184, 2011.

[53] X. Chen, Z. Ren, W. Liang et al., "c-Abl mediates angiotensin II-induced apoptosis in podocytes," Journal of Molecular Histology, vol. 44, no. 5, pp. 597-608, 2013. 
[54] V. P. Singh, A. Bali, N. Singh, and A. S. Jaggi, "Advanced glycation end products and diabetic complications," The Korean Journal of Physiology \& Pharmacology, vol. 18, no. 1, pp. 1-14, 2014.

[55] A. Rivero, C. Mora, M. Muros, J. García, H. Herrera, and J. F. Navarro-González, "Pathogenic perspectives for the role of inflammation in diabetic nephropathy," Clinical Science, vol. 116, no. 6, pp. 479-492, 2009.

[56] P. Gao, F.-F. He, H. Tang et al., "NADPH oxidase-induced NALP3 inflammasome activation is driven by thioredoxininteracting protein which contributes to podocyte injury in hyperglycemia," Journal of Diabetes Research, vol. 2015, Article ID 504761, 12 pages, 2015.

[57] K. Kanasaki, G. Taduri, and D. Koya, "Diabetic nephropathy: the role of inflammation in fibroblast activation and kidney fibrosis," Frontiers in Endocrinology, vol. 4, p. 7, 2013.

[58] M. B. Duran-Salgado and A. F. Rubio-Guerra, "Diabetic nephropathy and inflammation," World Journal of Diabetes, vol. 5, no. 3, pp. 393-398, 2014.

[59] S. Morano, R. Cipriani, C. Santangelo et al., “Angiotensin blockade and matrix synthesis by glomerular epithelial cells in high glucose: a further experimental insight into the pathophysiology of diabetic nephropathy," Clinical Therapeutics, vol. 159, no. 3, pp. 151-154, 2008.

[60] T. Chawla, D. Sharma, and A. Singh, "Role of the renin angiotensin system in diabetic nephropathy," World Journal of Diabetes, vol. 1, no. 5, pp. 141-145, 2010.

[61] M. H. A. Muskiet, M. M. Smits, L. M. Morsink, and M. Diamant, "The gut-renal axis: do incretin-based agents confer renoprotection in diabetes?," Nature Reviews Nephrology, vol. 10, pp. 88-103, 2014.

[62] S. M. Marshall, "Recent advances in diabetic nephropathy," Postgraduate Medical Journal, vol. 80, pp. 624-633, 2004.

[63] E. Bortoloso, D. D. Prete, M. Dalla Vestra et al., "Quantitative and qualitative changes in vascular endothelial growth factor gene expression in glomeruli of patients with type 2 diabetes," European Journal of Endocrinology, vol. 150, pp. 799-807, 2004.

[64] H. J. Baelde, M. Eikmans, D. W. Lappin et al., "Reduction of VEGF-A and CTGF expression in diabetic nephropathy is associated with podocyte loss," Kidney International, vol. 71, pp. 637-645, 2007.

[65] J. J. Li, S. J. Kwak, D. S. Jung et al., "Podocyte biology in diabetic nephropathy," Kidney International, vol. 106, pp. S36-S42, 2007.

[66] J. S. Lin and K. Susztak, "Podocytes: the weakest link in diabetic kidney disease?," Current Diabetes Reports, vol. 16, no. 5 , p. 45, 2016.

[67] J. R. Sowers, A. Whaley-Connell, and M. R. Hayden, "The role of overweight and obesity in the cardiorenal syndrome," Cardiorenal Medicine, vol. 1, pp. 5-12, 2011.

[68] P. Schlatter, C. Beglinger, J. Drewe, and H. Gutmann, "Glucagon-like peptide 1 receptor expression in primary porcine proximal tubular cells," Regulatory Peptides, vol. 141, pp. 120-128, 2007.

[69] A. Aroor, S. McKarns, R. Nistala et al., "DPP-4 inhibitors as therapeutic modulators of immune cell function and associated cardiovascular and renal insulin resistance in obesity and diabetes," Cardiorenal Medicine, vol. 3, no. 1, pp. 4856, 2013.
[70] M. Yu, C. Moreno, K. M. Hoagland et al., "Antihypertensive effect of glucagonlike peptide 1 in Dahl salt-sensitive rats," Journal of Hypertension, vol. 21, pp. 1125-1135, 2003.

[71] E. P. Jensen, S. S. Poulsen, H. Kissow et al., "Activation of GLP-1 receptors on vascular smooth muscle cells reduces the autoregulatory response in afferent arterioles and increases renal blood flow," American Journal of Physiology Renal Physiology, vol. 308, no. 8, pp. F867-F877, 2015.

[72] T. A. Salles, L. dos Santos, V. G. Barauna, and A. C. C. Girardi, "Potential role of dipeptidyl peptidase IV in the pathophysiology of heart failure," International Journal of Molecular Sciences, vol. 16, no. 2, pp. 4226-4249, 2015.

[73] E. E. Mulvihill and D. J. Drucker, "Metabolic implications of DPP-4 inhibition," Endocrine Reviews, vol. 35, no. 6, pp. 992-1019, 2014.

[74] K. V. Websky, C. Reichetzedera, and B. Hochera, "Physiology and pathophysiology of incretins in the kidney," Current Opinion in Nephrology and Hypertension, vol. 23, no. 1, pp. 54-60, 2014.

[75] S. Shi, D. Koya, and K. Kanasaki, "Dipeptidyl peptidase-4 and kidney fibrosis in diabetes," Fibrogenesis \& Tissue Repair, vol. 9, p. 1, 2016.

[76] G. P. Fadini, E. Boscaro, M. Albiero et al., "The oral dipeptidyl peptidase-4 inhibitor sitagliptin increases circulating endothelial progenitor cells in patients with type 2 diabetes mellitus. Possible role of stromal derived factor- $1 \alpha$," Diabetes Care, vol. 33, pp. 1607-1609, 2010.

[77] G. L. Plosker, "Sitagliptin: a review of its use in patients with type 2 diabetes mellitus," Drugs, vol. 74, pp. 223-242, 2014.

[78] G. A. Herman, C. Stevens, K. Van Dyck et al., "Pharmacokinetics and pharmacodynamics of sitagliptin, an inhibitor of dipeptidyl peptidase IV, in healthy subjects: results from two randomized, double-blind, placebo-controlled studies with single oral doses," Journal of Clinical Pharmacology and Therapeutics, vol. 78, no. 6, pp. 675-688, 2005.

[79] A. J. Bergman, J. Cote, B. Yi et al., "Effect of renal insufficiency on the pharmacokinetics of sitagliptin, a dipeptidyl peptidase-4 inhibitor," Diabetes Care, vol. 30, no. 7, pp. 1862-1864, 2007.

[80] E. M. Migoya, C. H. Stevens, A. J. Bergman et al., "Effect of moderate hepatic insufficiency on the pharmacokinetics of sitagliptin," Canadian Journal of Clinical Pharmacology, vol. 16, no. 1, pp. 165-170, 2009.

[81] J. C. Arjona Ferreira, M. Marre, N. Barzilai et al., "Efficacy and safety of sitagliptin versus glipizide in patients with type 2 diabetes and moderate-to-severe chronic renal insufficiency," Diabetes Care, vol. 36, no. 5, pp. 1067-1073, 2013.

[82] J. J. Neumiller and I. B. Hirsch, "Management of hyperglycemia in diabetic kidney disease," Diabetes Spectrum, vol. 28, no. 3, pp. 214-219, 2015.

[83] C. C. R. Betônico, S. M. O. Titan, M. L. C. Correa-Giannella, M. Nery, and M. Queiroz, "Management of diabetes mellitus in individuals with chronic kidney disease: therapeutic perspectives and glycemic control," Clinics, vol. 71, no. 1, pp. 47-53, 2016.

[84] D. Kim, L. Wang, M. Beconi et al., "2(2R)-4-oxo-4-[3-(trifluoromethyl)-5,6-dihydro[1, 2, 4] triazolo[4,3-a]pyrazin$7(8 \mathrm{H})$ - yl]-1-(2,4,5-trifluorophenyl)butan-2-amine: a potent, orally active dipeptidyl peptidase IV inhibitor for the treatment of type 2 diabetes," Journal of Medicinal Chemistry, vol. 48, no. 1, pp. 141-151, 2005. 
[85] S. E. Inzucchi and D. K. McGuire, "New drugs for the treatment of diabetes: part II. Incretin-based therapy and beyond," Circulation, vol. 117, no. 4, pp. 574-584, 2008.

[86] B. Ahrén, "Dipeptidyl peptidase- 4 inhibitors: clinical data and clinical implications," Diabetes Care, vol. 30, no. 6, pp. 1344-1350, 2007.

[87] R. K. Campbell, "Rationale for dipeptidyl peptidase 4 inhibitors: a new class of oral agents for the treatment of type 2 diabetes mellitus," Annals of Pharmacotherapy, vol. 41, no. 1, pp. 51-60, 2007.

[88] J. Rosenstock and B. Zinman, "Dipeptidyl peptidase-4 inhibitors and the management of type 2 diabetes mellitus," Current Opinion in Endocrinology, Diabetes, and Obesity, vol. 14, no. 2, pp. 98-107, 2007.

[89] L. L. Baggio and D. J. Drucker, "Biology of incretins: GLP-1 and GIP,” Gastroenterology, vol. 132, no. 6, pp. 21312157, 2007.

[90] J. F. Gautier, S. P. Choukem, and J. Girard, "Physiology of incretins (GIP and GLP-1) and abnormalities in type 2 diabetes," Diabetes \& Metabolism, vol. 34, Supplement 2, pp. S65-S72, 2008.

[91] C. F. Deacon, P. Danielsen, L. Klarskov, M. Olesen, and J. J. Holst, "Dipeptidyl peptidase IV inhibition reduces the degradation and clearance of GIP and potentiates its insulinotropic and antihyperglycemic effects in anesthetized pigs," Diabetes, vol. 50, no. 7, pp. 1588-1597, 2001.

[92] G. A. Herman, A. Bergman, F. Liu et al., "Pharmacokinetics and pharmacodynamic effects of the oral DPP-4 inhibitor sitagliptin in middle-aged obese subjects," Journal of Clinical Pharmacology, vol. 46, no. 8, pp. 876-886, 2006.

[93] B. Ahrén, E. Simonsson, H. Larsson et al., "Inhibition of dipeptidyl peptidase IV improves metabolic control over a 4-week study period in type 2 diabetes," Diabetes Care, vol. 25, no. 5, pp. 869-875, 2002.

[94] B. Ahrén, "Insulin plus incretin: a glucose-lowering strategy for type 2-diabetes," World Journal of Diabetes, vol. 5, no. 1, pp. 40-51, 2014.

[95] A. J. Scheen, "Pharmacokinetics of dipeptidylpeptidase-4 inhibitors," Diabetes Obesity and Metabolism, vol. 12, no. 8, pp. 648-658, 2010.

[96] S. S. Engel, E. Round, G. T. Golm, K. D. Kaufman, and B. J. Goldstein, "Safety and tolerability of sitagliptin in type 2 diabetes: pooled analysis of 25 clinical studies," Diabetes Therapy, vol. 4, no. 1, pp. 119-145, 2013.

[97] K. Garg, C. D. Tripathi, and S. Kumar, "Clinical review of sitagliptin: a DPP-4 inhibitor," Journal of the Association of Physicians of India, vol. 61, pp. 57-61, 2013.

[98] K. Esposito, P. Chiodini, M. I. Maiorino, G. Bellastella, A. Capuano, and D. Giugliano, "Glycaemic durability with dipeptidyl peptidase- 4 inhibitors in type 2 diabetes: a systematic review and meta-analysis of long-term randomised controlled trials," BMJ Open, vol. 4, article e005442, 2014.

[99] J. Mu, J. Woods, and Y. P. Zhou, "Chronic inhibition of dipeptidyl peptidase- 4 with a sitagliptin analog preserves pancreatic $\beta$-cell mass and function in a rodent model of type 2 diabetes," Diabetes, vol. 55, no. 6, pp. 1695-1704, 2006.

[100] J. Mu, A. Petrov, G. J. Eiermann et al., "Inhibition of DPP-4 with sitagliptin improves glycemic control and restores islet cell mass and function in a rodent model of type 2 diabetes," European Journal of Pharmacology, vol. 623, pp. 148-154, 2009.
[101] L. Ferreira, E. Teixeira-de-Lemos, F. Pinto et al., "Effects of sitagliptin treatment on dysmetabolism, inflammation, and oxidative stress in an animal model of type 2 diabetes (ZDF rat)," Mediators of Inflammation, vol. 2010, Article ID 592760, 11 pages, 2010.

[102] M. Ji, L. Xia, J. Cao, and D. Zou, "Sitagliptin/metformin versus insulin glargine combined with metformin in obese subjects with newly diagnosed type 2 diabetes," Medicine, vol. 95, no. 11, article e2961, 2016.

[103] Y. Kondo, N. Harada, A. Hamasaki et al., "Sitagliptin monotherapy has better effect on insulinogenic index than glimepiride monotherapy in Japanese patients with type 2 diabetes mellitus: a 52-week, multicenter, parallel-group randomized controlled trial," Diabetology \& Metabolic Syndrome, vol. 8, no. 15, 2016.

[104] X. Ren, G. Liu, Y. Wang et al., "Influence of dipeptidyl peptidase-IV inhibitor sitagliptin on extracellular signalregulated kinases $1 / 2$ signaling in rats with diabetic nephropathy," Pharmacology, vol. 100, pp. 1-13, 2017.

[105] B. Gallwitz, "Extra-pancreatic effects of incretin-based therapies," Endocrine, vol. 47, no. 2, pp. 360-371, 2014.

[106] E. J. Verspohl, "Novel therapeutics for type 2 diabetes: incretin hormone mimetics (glucagon-like-peptide-1 receptor agonists) and dipeptidyl peptidase-4 inhibitors," Pharmacology \& Therapeutics, vol. 124, pp. 113-138, 2009.

[107] R. E. Van Genugten, D. H. van Raalte, and M. Diamant, "Dipeptidyl peptidase-4 inhibitors and preservation of pancreatic islet-cell function: a critical appraisal of the evidence," Diabetes Obesity and Metabolism, vol. 14, pp. 101-111, 2012.

[108] Y. Zeng, C. Li, M. Guan et al., "The DPP-4 inhibitor sitagliptin attenuates the progress of atherosclerosis in apolipoprotein-E-knockout mice via AMPK- and MAPKdependent mechanisms," Cardiovascular Diabetology, vol. 13, no. 32, 2014.

[109] A. V. Matveyenko, S. Dry, H. I. Cox et al., "Beneficial endocrine but adverse exocrine effects of sitagliptin in the human islet amyloid polypeptide transgenic rat model of type 2 diabetes: interactions with metformin," Diabetes, vol. 58, no. 7, pp. 1604-1615, 2009.

[110] Y. S. Liu, Z. W. Huang, L. Wang et al., "Sitagliptin alleviated myocardial remodeling of the left ventricle and improved cardiac diastolic dysfunction in diabetic rats," Journal of Pharmacological Sciences, vol. 127, no. 3, pp. 260-274, 2015.

[111] L. M. McCormick, A. C. Kydd, P. A. Read et al., "Chronic dipeptidyl peptidase- 4 inhibition with sitagliptin is associated with sustained protection against ischemic left ventricular dysfunction in a pilot study of patients with type 2 diabetes mellitus and coronary artery disease," Circulation: Cardiovascular Imaging, vol. 7, no. 2, pp. 274-281, 2014.

[112] N. Apaijai, H. Pintana, S. C. Chattipakorn, and N. Chattipakorn, "Effects of vildagliptin versus sitagliptin, on cardiac function, heart rate variability and mitochondrial function in obese insulin resistant rats," British Journal of Pharmacology, vol. 169, no. 5, pp. 1048-1057, 2013.

[113] B. Picatoste, E. Ramírez, A. Caro-Vadillo et al., "Sitagliptin reduces cardiac apoptosis, hypertrophy and fibrosis primarily by insulin-dependent mechanisms in experimental type-II diabetes. Potential roles of GLP-1 isoforms," PLoS One, vol. 8, no. 10, article e78330, 2013.

[114] P. A. Read, F. Z. Khan, P. M. Heck, S. P. Hoole, and D. P. Dutka, "DPP-4 inhibition by sitagliptin improves the myocardial response to dobutamine stress and mitigates 
stunning in a pilot study of patients with coronary artery disease," Circulation. Cardiovascular Imaging, vol. 3, no. 2, pp. 195-201, 2010.

[115] M. T. Kelleni, E. F. Amin, and A. M. Abdelrahman, "Effect of metformin and sitagliptin on doxorubicin-induced cardiotoxicity in rats: impact of oxidative stress, inflammation, and apoptosis," Journal of Toxicology, vol. 2015, Article ID 424813, 8 pages, 2015.

[116] T. Mita, N. Katakami, T. Shiraiwa et al., "Sitagliptin attenuates the progression of carotid intima-media thickening in insulin-treated patients with type 2 diabetes: the sitagliptin preventive study of intima-media thickness evaluation (spike): a randomized controlled trial," Diabetes Care, vol. 39, no. 3, pp. 455-464, 2016.

[117] R. E. Amori, J. Lau, and A. G. Pittas, "Efficacy and safety of incretin therapy in type 2 diabetes: systematic review and meta-analysis," Journal of the American Medical Association, vol. 298, no. 2, pp. 194-206, 2007.

[118] M. Fan, Y. Li, and S. Zhang, "Effects of sitagliptin on lipid profiles in patients with type 2 diabetes mellitus: a metaanalysis of randomized clinical trials," Medicine, vol. 95, no. 2, pp. 1-9, 2016.

[119] P. C. M. Van Poppel, M. G. Netea, P. Smits, and C. Tack, "Vildagliptin improves endothelium-dependent vasodilatation in type 2 diabetes," Diabetes Care, vol. 34, no. 9, pp. 2072-2077, 2011.

[120] J. S. Yoon and H. W. Lee, "Understanding the cardiovascular effects of incretin," Diabetes \& Metabolism Journal, vol. 35, no. 5, pp. 437-443, 2011.

[121] C. Mega, H. Vala, P. Rodrigues-Santos et al., "Sitagliptin prevents aggravation of endocrine and exocrine pancreatic damage in the Zucker diabetic fatty rat - focus on amelioration of metabolic profile and tissue cytoprotective properties," Diabetology \& Metabolic Syndrome, vol. 6, no. 1, p. 42, 2014.

[122] A. Gonçalves, E. Leal, A. Paiva et al., "Protective effects of the dipeptidyl peptidase IV inhibitor sitagliptin in the bloodretinal barrier in a type 2 diabetes animal model," Diabetes, Obesity and Metabolism, vol. 14, no. 5, pp. 454-463, 2012.

[123] A. Gonçalves, C. Marques, E. Leal et al., "Dipeptidyl peptidase-IV inhibition prevents blood-retinal barrier breakdown, inflammation and neuronal cell death in the retina of type 1 diabetic rats," Biochimica et Biophysica Acta (BBA) Molecular Basis of Disease, vol. 1842, no. 9, pp. 1454-1463, 2014.

[124] C. Mega, E. T. de Lemos, H. Vala et al., "Diabetic nephropathy amelioration by a low dose sitagliptin in an animal model of type 2 diabetes (Zucker diabetic fatty rat)," Experimental Diabetes Research, vol. 2011, Article ID 162092, 12 pages, 2011.

[125] A. Maida, T. Hansotia, C. Longuet, T. Seino, and D. J. Drucker, "Differential importance of glucose-dependent insulinotropic polypeptide vs glucagon-like peptide 1 receptor signaling for $\beta$ cell survival in mice," Gastroenterology, vol. 137, pp. 2146-2157, 2009.

[126] J. A. Yeom, E. S. Kim, H. S. Park et al., "Both sitagliptin analogue \& pioglitazone preserve the $\beta$-cell proportion in the islets with different mechanism in non-obese and obese diabetic mice," BMB Reports, vol. 44, no. 11, pp. 713-718, 2011.

[127] Y. Takeda, Y. Fujita, and J. Honjo, "Reduction of both beta cell death and alpha cell proliferation by dipeptidyl peptidase- 4 inhibition in a streptozotocin-induced model of diabetes in mice," Diabetologia, vol. 55, no. 2, pp. 404-412, 2012.

[128] S. Karabulut, Z. M. Coskunb, and S. Bolkent, "Immunohistochemical, apoptotic and biochemical changes by dipeptidyl peptidase-4 inhibitor-sitagliptin in type-2 diabetic rats," Pharmacological Reports, vol. 67, no. 5, pp. 846-853, 2015.

[129] J. Shirakawa, T. Okuyama, M. Kyohara et al., "DPP-4 inhibition improves early mortality, $\beta$ cell function, and adipose tissue inflammation in $\mathrm{db} / \mathrm{db}$ mice fed a diet containing sucrose and linoleic acid," Diabetology \& Metabolic Syndrome, vol. 8, no. 16, 2016.

[130] A. D. Dobrian, Q. Ma, J. W. Lindsay et al., "Dipeptidyl peptidase IV inhibitor sitagliptin reduces local inflammation in adipose tissue and in pancreatic islets of obese mice," American Journal of Physiology: Endocrinology and Metabolism, vol. 300, no. 2, pp. E410-E421, 2011.

[131] N. Satoh-Asahara, Y. Sasaki, H. Wada et al., "A dipeptidyl peptidase-4 inhibitor, sitagliptin, exerts anti-inflammatory effects in type 2 diabetic patients," Metabolism, vol. 62, no. 3, pp. 347-351, 2013.

[132] G. Derosa, A. Carbone, A. D’Angelo et al., "Variations in inflammatory biomarkers following the addition of sitagliptin in patients with type 2 diabetes not controlled with metformin," Internal Medicine, vol. 52, no. 19, pp. 2179-2187, 2013.

[133] F. Beguinot, "Tribbles homologue 3 (TRIB3) and the insulinresistance genes in type 2 diabetes," Diabetologia, vol. 53, pp. 1831-1834, 2010.

[134] S. Prudente, D. Scarpelli, M. Chandalia et al., "The trib3 Q84R polymorphism and risk of early-onset type 2 diabetes," Journal of Clinical Endocrinology \& Metabolism, vol. 94, no. 1, pp. 190-196, 2009.

[135] J. Shirakawa, H. Fujii, K. Ohnuma et al., "Diet-induced adipose tissue inflammation and liver steatosis are prevented by DPP-4 inhibition in diabetic mice," Diabetes, vol. 60, pp. 1246-1257, 2011.

[136] S. Oyadomari, H. P. Harding, Y. Zhang, M. Oyadomari, and D. Ron, "Dephosphorylation of translation initiation factor $2 \alpha$ enhances glucose tolerance and attenuates hepatosteatosis in mice," Cell Metabolism, vol. 7, pp. 520-532, 2008.

[137] V. Aviv, I. Meivar-Levy, I. H. Rachmut, T. Rubinek, E. Mor, and S. Ferber, "Exendin-4 promotes liver cell proliferation and enhances PDX-1-induced liver to pancreas transdifferentiation," The Journal of Biological Chemistry, vol. 284, no. 48, pp. 33509-33520, 2009.

[138] L. Gaetaniello, M. Fiore, S. de Filippo, N. Pozzi, S. Tamasi, and C. Pignata, "Occupancy of dipeptidyl peptidase IV activates an associated tyrosine kinase and triggers an apoptotic signal in human hepatocarcinoma cells," Hepatology, vol. 27, pp. 934-942, 1998.

[139] M. E. Kelany, T. M. Hakami, A. H. Omar, and M. A. Abdallah, "Combination of sitagliptin and insulin against type 2 diabetes mellitus with neuropathy in rats: neuroprotection and role of oxidative and inflammation stress," Pharmacology, vol. 98, pp. 242-250, 2016.

[140] B. F. Schrijvers, A. Flyvbjerg, R. G. Tilton, N. H. Lameire, and A. S. D. Vriese, "A neutralizing VEGF antibody prevents glomerular hypertrophy in a model of obese type 2 diabetes, the Zucker diabetic fatty rat," Nephrology Dialysis Transplantation, vol. 21, no. 2, pp. 324-329, 2006. 
[141] L. Liu, J. Liu, W. T. Wong et al., "Dipeptidyl peptidase 4 inhibitor sitagliptin protects endothelial function in hypertension through a glucagon-like peptide 1-dependent mechanism," Hypertension, vol. 60, pp. 833-841, 2012.

[142] S. Kröller-Schön, M. Knorr, M. Hausding et al., "Glucose-independent improvement of vascular dysfunction in experimental sepsis by dipeptidyl-peptidase 4 inhibition," Cardiovascular Research, vol. 96, pp. 140-149, 2012.

[143] I. Kawasaki, Y. Hiura, A. Tamai et al., "Sitagliptin reduces the urine albumin-to-creatinine ratio in type 2 diabetes through decreasing both blood pressure and estimated glomerular filtration rate," Journal of Diabetes, vol. 7, no. 1, pp. 41-46, 2015.

[144] L. M. Russo, R. M. Sandoval, S. B. Campos, B. A. Molitoris, W. D. Comper, and D. Brown, "Impaired tubular uptake explains albuminuria in early diabetic nephropathy," Journal of the American Society of Nephrology, vol. 20, no. 3, pp. 489494, 2009.

[145] G. B. Peres and Y. M. Michelacci, "The role of proximal tubular cells in the early stages of diabetic nephropathy," Journal of Diabetes \& Metabolism, vol. 6, p. 551, 2015.

[146] A. C. Girardi, B. C. Degray, T. Nagy, D. Biemesderfer, and P. S. Aronson, "Association of $\mathrm{Na}^{+}-\mathrm{H}^{+}$exchanger isoform NHE3 and dipeptidyl peptidase IV in the renal proximal tubule," The Journal of Biological Chemistry, vol. 276, no. 49, pp. 46671-46677, 2001.

[147] D. F. Arruda-Junior, F. L. Martins, R. Dariolli et al., "Dipeptidyl peptidase IV inhibition exerts renoprotective effects in rats with established heart failure," Frontiers in Physiology, vol. 7, p. 293, 2016.

[148] R. Nistala, J. Habibi, G. Lastra et al., "Prevention of obesityinduced renal injury in male mice by DPP4 inhibition," Endocrinology, vol. 155, no. 6, pp. 2266-2276, 2014.

[149] R. Nistala, J. Habibi, A. Aroor et al., "DPP4 inhibition attenuates filtration barrier injury and oxidant stress in the zucker obese rat," Obesity, vol. 22, no. 10, pp. 21722179, 2014.

[150] W. J. Liu, S. H. Xie, Y. N. Liu et al., "Dipeptidyl peptidase IV inhibitor attenuates kidney injury in streptozotocin-induced diabetic rats," Journal of Pharmacology and Experimental Therapeutics, vol. 340, pp. 248-255, 2012.

[151] A. Aroor, M. Zuberek, C. Duta et al., "Angiotensin II stimulation of DPP4 activity regulates megalin in the proximal tubules," International Journal of Molecular Sciences, vol. 17, no. $5,2016$.

[152] B. Hocher, C. Reichetzeder, and M. L. Alter, "Renal and cardiac effects of DPP-4 inhibitors - from preclinical development to clinical research," Kidney and Blood Pressure Research, vol. 36, pp. 65-84, 2012.

[153] B. P. Pacheco, R. O. Crajoinas, G. K. Couto et al., "Dipeptidyl peptidase IV inhibition attenuates blood pressure rising in young spontaneously hypertensive rats," Journal of Hypertension, vol. 29, pp. 520-528, 2011.

[154] S. Saha, Y. Li, and M. B. Anand-Srivastava, "Reduced levels of cyclic AMP contribute to the enhanced oxidative stress in vascular smooth muscle cells from spontaneously hypertensive rats," Canadian Journal of Physiology and Pharmacology, vol. 86, pp. 190-198, 2008.

[155] A. Avogaro and G. P. Fadini, "The effects of dipeptidyl peptidase- 4 inhibition on microvascular diabetes complications," Diabetes Care, vol. 37, no. 10, pp. 2884-2894, 2014.
[156] A. A. Eddy, "Serine proteases, inhibitors and receptors in renal fibrosis," Thrombosis and Haemostasis, vol. 101, no. 4, pp. 656-664, 2009.

[157] G. Tramonti and Y. S. Kanwar, "Tubular biomarkers to assess progression of diabetic nephropathy," Kidney International, vol. 79, no. 10, pp. 1042-1044, 2011.

[158] S. Hoshi, Y. Shu, F. Yoshida et al., "Podocyte injury promotes progressive nephropathy in zucker diabetic fatty rats," Laboratory Investigation, vol. 82, no. 1, pp. 25-35, 2002.

[159] N. Gassler, M. Elger, B. Kränzlin et al., "Podocyte injury underlies the progression of focal segmental glomerulosclerosis in the fa/fa Zucker rat," Kidney International, vol. 60, no. 1, pp. 106-116, 2001.

[160] T. W. Tervaert, A. L. Mooyaart, K. Amann et al., "Pathologic classification of diabetic nephropathy," Journal of the American Society of Nephrology, vol. 21, no. 4, pp. 556$563,2010$.

[161] K. White, "Histological appearance of diabetic nephropathy," Diapedia 7105002828 rev., no. 5, 2014.

[162] U. Panchapakesan and C. Pollock, "The role of dipeptidyl peptidase -4 inhibitors in diabetic kidney disease," Frontiers in Immunology, vol. 6, p. 443, 2015.

[163] H. S. Min, J. E. Kim, M. H. Lee et al., "Dipeptidyl peptidase IV inhibitor protects against renal interstitial fibrosis in a mouse model of ureteral obstruction," Laboratory Investigation, vol. 94, no. 6, pp. 598-607, 2014.

[164] S. Shi, S. P. Srivastava, M. Kanasaki et al., "Interactions of DPP-4 and integrin $\beta 1$ influences endothelial-tomesenchymal transition," Kidney International, vol. 88, no. 3, pp. 479-489, 2015.

[165] G. Tonolo and S. Cherchi, "Tubulointerstitial disease in diabetic nephropathy," International Journal of Nephrology and Renovascular Disease, vol. 7, pp. 107-115, 2014.

[166] P. Vavrinec, R. H. Henning, S. W. Landheer et al., "Vildagliptin restores renal myogenic function and attenuates renal sclerosis independently of effects on blood glucose or proteinuria in Zucker diabetic fatty rat," Current Vascular Pharmacology, vol. 12, pp. 836-844, 2014.

[167] I. Raz, M. Hanefeld, L. Xu et al., "Efficacy and safety of the dipeptidyl peptidase-4 inhibitor sitagliptin as monotherapy in patients with type 2 diabetes mellitus," Diabetologia, vol. 49, no. 11, pp. 2564-2571, 2006.

[168] V. Gupta and S. Kalra, "Choosing a gliptin," Indian Journal of Endocrinology and Metabolism, vol. 15, no. 4, pp. 298-308, 2011.

[169] Y. Wang, S. Landheer, W. H. van Gilst et al., “Attenuation of renovascular damage in Zucker diabetic fatty rat by NWT-03, an egg protein hydrolysate with ACE- and DPP-4-inhibitory activity," PLoS One, vol. 7, no. 10, article e46781, 2012.

[170] H. Y. Jin, W. J. Liu, J. H. Park, H. S. Baek, and T. S. Park, "Effect of dipeptidyl peptidase-IV (DPP-IV) inhibitor (vildagliptin) on peripheral nerves in streptozotocininduced diabetic rats," Archives of Medical Research, vol. 40, pp. 536-544, 2009.

[171] Y. Ishibashi, S. Yamagishi, T. Matsui et al., "Pravastatin inhibits advanced glycation end products (AGEs)-induced proximal tubular cell apoptosis and injury by reducing receptor for AGEs (RAGE) level," Metabolism, vol. 61, pp. 1067-1072, 2012. 
[172] T. Tanaka, Y. Higashijima, T. Wada, and M. Nangaku, "The potential for renoprotection with incretin-based drugs," Kidney International, vol. 86, pp. 701-711, 2014.

[173] J. L. Górriz, J. Nieto, J. F. Navarro-González, P. Molina, A. Martínez-Castelao, and L. M. Pallardó, "Nephroprotection by hypoglycemic agents: do we have supporting data?," Journal of Clinical Medicine, vol. 4, no. 10, pp. 18661889, 2015.

[174] W. S. Silva Júnior, A. F. Godoy-Matos, and L. G. KraemerAguiar, "Dipeptidyl peptidase 4: a new link between diabetes mellitus and atherosclerosis?," Biomedical Research International, vol. 2015, Article ID 816164, 10 pages, 2015.

[175] V. Matheeussen, L. Baerts, G. De Meyer et al., "Expression and spatial heterogeneity of dipeptidyl peptidases in endothelial cells of conduct vessels and capillaries," Biological Chemistry, vol. 392, no. 3, pp. 189-198, 2011.

[176] T. Romacho, S. Vallejo, L. A. Villalobos et al., "Soluble dipeptidyl peptidase-4 induces microvascular endothelial dysfunction through proteinase-activated receptor-2 and thromboxane A2 release," Journal of Hypertension, vol. 34, no. 5, pp. 869-876, 2016.

[177] C. G. Yu, N. Zhang, S. S. Yuan et al., "Endothelial progenitor cells in diabetic microvascular complications: friends or foes?", Stem Cells International, vol. 2016, Article ID 1803989, 10 pages, 2016.

[178] R. H. Ahmed, H. Z. Huri, Z. Al-Hamodi, S. D. Salem, and S. Muniandy, "Serum levels of soluble CD26/dipeptidyl peptidase-IV in type 2 diabetes mellitus and its association with metabolic syndrome and therapy with antidiabetic agents in Malaysian subjects," PLoS One, vol. 10, no. 10, article e0140618, 2015.

[179] D. Röhrborn, N. Wronkowitz, and J. Eckel, "DPP-4 in diabetes," Frontiers in Immunology, vol. 6, p. 386, 2015.

[180] J. Donate-Correa, E. Martín-Núñez, M. Muros-de-Fuentes, C. Mora-Fernández, and J. F. Navarro-González, "Inflammatory cytokines in diabetic nephropathy," Journal of Diabetes Research, vol. 2015, Article ID 948417, 9 pages, 2015.

[181] J. F. Navarro and C. Mora, "Diabetes, inflammation, proinflammatory cytokines, and diabetic nephropathy," The Scientific World Journal, vol. 6, pp. 908-917, 2006.

[182] X. Ren, G. Liu, Y. Wang et al., "Influence of dipeptidyl peptidase-iv inhibitor sitagliptin on extracellular signalregulated kinases $1 / 2$ signaling in rats with diabetic nephropathy," Pharmacology, vol. 100, no. 1-2, pp. 1-13, 2017.

[183] J. S. Nielsen and K. M. McNagny, "Novel functions of the CD34 family," Journal of Cell Science, vol. 121, Part 22, pp. 3682-3692, 2008.

[184] J. H. Li, W. Wang, X. R. Huang et al., "Advanced glycation end products induce tubular epithelial-myofibroblast transition through the RAGE-ERK1/2 MAP kinase signaling pathway," The American Journal of Pathology, vol. 164, no. 4, pp. 1389-1397, 2004.

[185] K. B. Gomes, K. F. Rodrigues, and A. P. Fernandes, "The role of transforming growth factor-beta in diabetic nephropathy," International Journal of Medical Genetics, vol. 2014, Article ID 180270, 6 pages, 2014.

[186] F. Yang, T. Yu, K. Li, X. Jiang, J. Li, and J. Wang, "Sitagliptin reduces transforming growth factor- $\beta 1$ and platelet derived growth factor-BB in regulation of UAER in type 2 diabetic nephropathy stage III patients," Biomedical Research, vol. 28, no. 6, pp. 2571-2577, 2017.
[187] S. S. Bessa, T. A. Hussein, M. A. Morad, and A. M. Amer, "Urinary platelet-derived growth factor-BB as an early marker of nephropathy in patients with type 2 diabetes: an Egyptian study," Renal Failure, vol. 34, no. 6, pp. 670-675, 2012.

[188] Y. Ishibashi, Y. Nishino, T. Matsui, M. Takeuchi, and S. I. Yamagishi, "Glucagon-like peptide-1 suppresses advanced glycation end product-induced monocyte chemoattractant protein-1 expression in mesangial cells by reducing advanced glycation end product receptor level," Metabolism, vol. 60, no. 9, pp. 1271-1277, 2011.

[189] J. Li, M. Guan, C. Li et al., "The dipeptidyl peptidase-4 inhibitor sitagliptin protects against dyslipidemia-related kidney injury in apolipoprotein E knockout mice," International Journal of Molecular Sciences, vol. 15, pp. 11416-11434, 2014.

[190] H. S. Lee, "Mechanisms and consequences of hypertriglyceridemia and cellular lipid accumulation in chronic kidney disease and metabolic syndrome," Histology and Histopathology, vol. 26, no. 12, pp. 1599-1610, 2011.

[191] A. R. Martins and S. Mas, "Lipotoxicity and kidney," Portuguese Journal of Nephrology \& Hypertension, vol. 29, no. 4, pp. 306-315, 2015.

[192] S. J. Glastras, H. Chen, R. T. McGrath et al., "Effect of GLP-1 receptor activation on offspring kidney health in a rat model of maternal obesity," Scientific Reports, vol. 6, article 23525, 2016.

[193] F. A. Wagener, D. Dekker, J. H. Berden, A. Scharstuhl, and J. van der Vlag, "The role of reactive oxygen species in apoptosis of the diabetic kidney," Apoptosis, vol. 14, no. 12, pp. 1451-1458, 2009.

[194] M. D. Sanchez-Niño, A. Benito-Martin, and A. Ortiz, "New paradigms in cell death in human diabetic nephropathy," Kidney International, vol. 78, no. 8, pp. 737-744, 2010.

[195] J. Vaghasiya, N. Sheth, Y. Bhalodia, and R. Manek, "Sitagliptin protects renal ischemia reperfusion induced renal damage in diabetes," Regulatory Peptides, vol. 166, no. 1-3, pp. 48-54, 2011.

[196] H. Hendarto, T. Inoguchi, Y. Maeda et al., "GLP-1 analog liraglutide protects against oxidative stress and albuminuria in streptozotocin-induced diabetic rats via protein kinase A mediated inhibition of renal $\mathrm{NAD}(\mathrm{P}) \mathrm{H}$ oxidases," Metabolism, vol. 61, no. 10, pp. 1422-1434, 2012.

[197] R. Kodera, K. Shikata, T. Takasuta et al., "Dipeptidyl peptidase-4 inhibitor ameliorates early renal injury through its antiinflammatory action in a rat model of type 1 diabetes," Biochemical and Biophysical Research Communications, vol. 443, no. 3, pp. 828-833, 2014.

[198] S. Nakashima, T. Matsui, M. Takeuchi, and S. I. Yamagishi, "Linagliptin blocks renal damage in type 1 diabetic rats by suppressing advanced glycation end products-receptor axis," Hormone and Metabolic Research, vol. 46, pp. 717-721, 2014.

[199] T. Matsui, S. Nakashima, Y. Nishino et al., "Dipeptidyl peptidase- 4 deficiency protects against experimental diabetic nephropathy partly by blocking the advanced glycation end products-receptor axis," Laboratory Investigation, vol. 95, no. 5, pp. 525-533, 2015. 


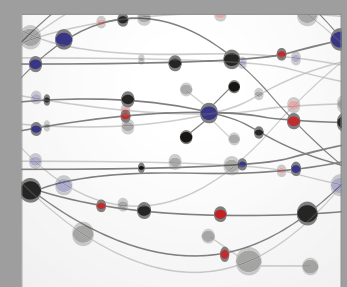

The Scientific World Journal
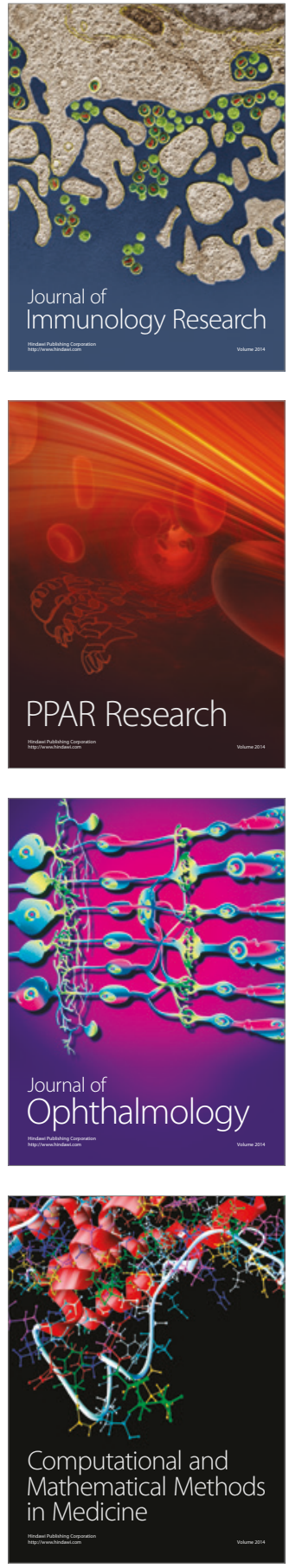

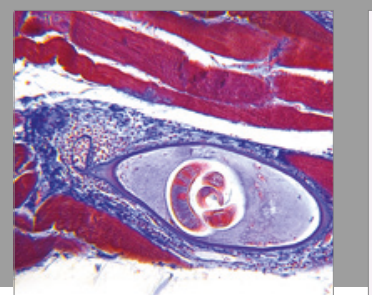

Gastroenterology Research and Practice
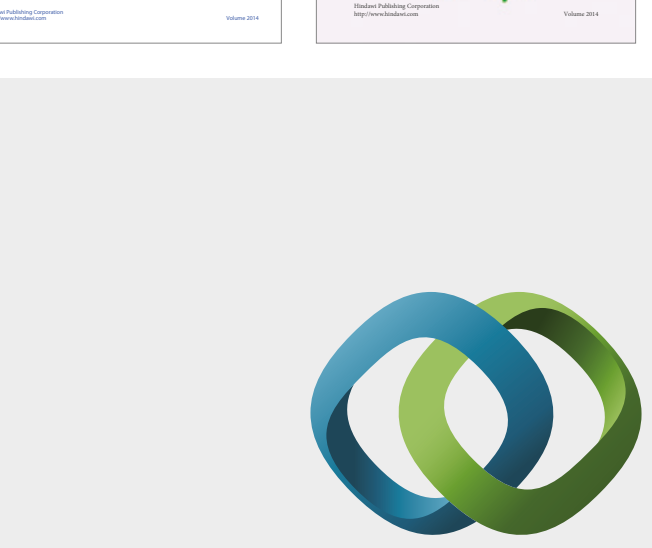

\section{Hindawi}

Submit your manuscripts at

https://www.hindawi.com
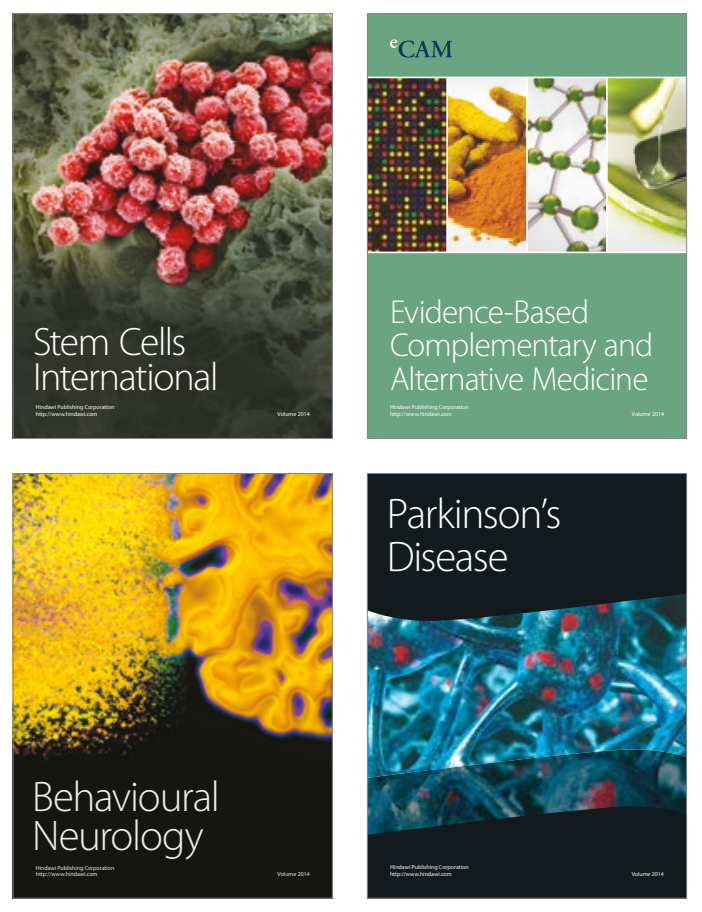
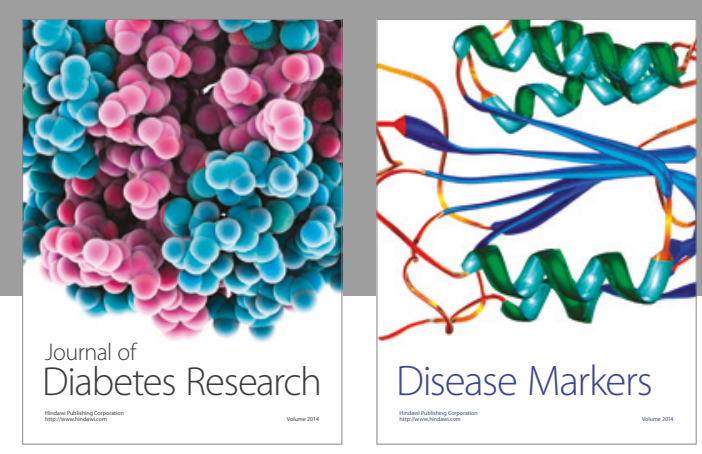

Disease Markers
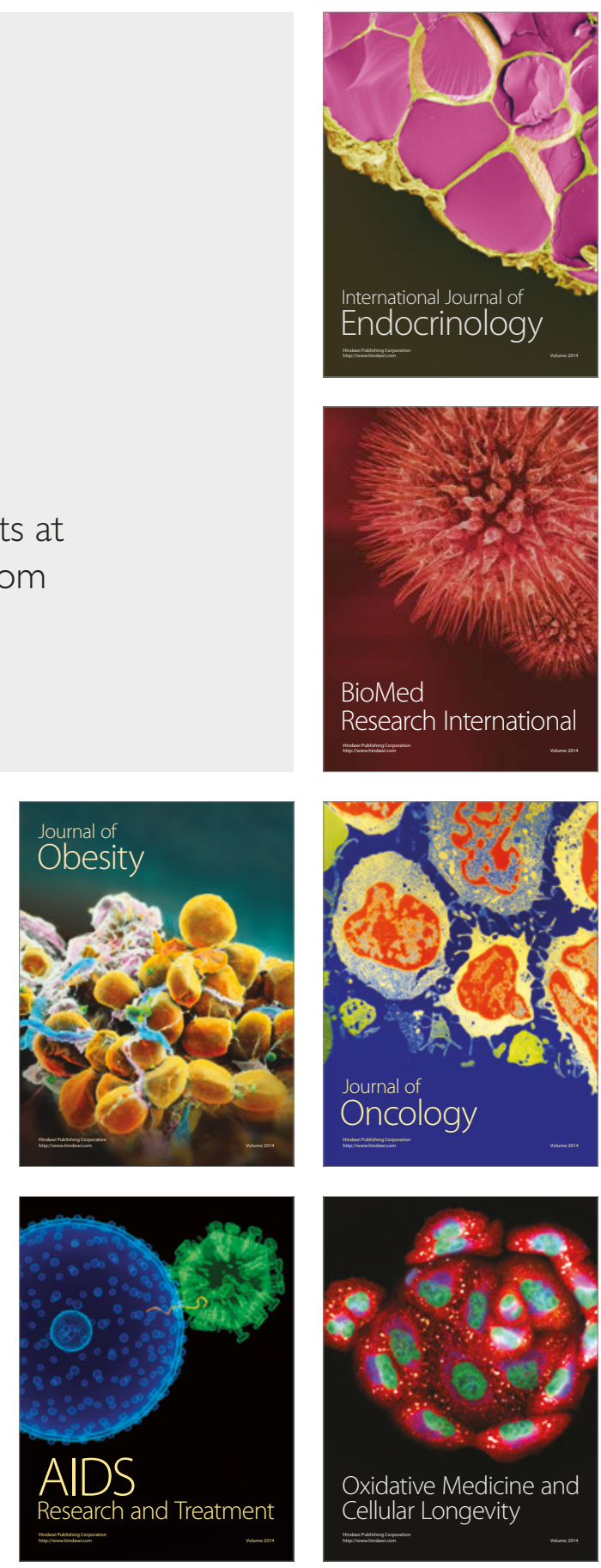